\title{
GALLOYL CARBOHYDRATES WITH ANTIANGIOGENIC ACTIVITY MEDIATED BY CAPILLARY MORPHOGENESIS GENE 2 (CMG2) PROTEIN BINDING
}

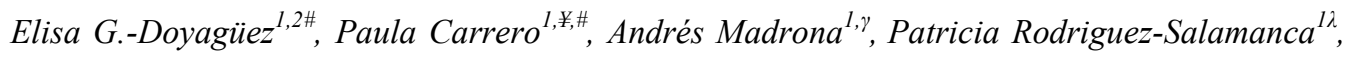
Belén Martínez-Gualda ${ }^{1, \pi}$, María José Camarasa ${ }^{1}$, María Luisa Jimeno ${ }^{2}$, Philip R. Bennallack ${ }^{3}$, Jordan G. Finnell ${ }^{4, \varphi}$, Tsz Ming Tsang ${ }^{4}$, Kenneth A. Christensen ${ }^{4}$, Ana San-Félix ${ }^{*}$, Michael S. Rogers $^{* 3}$

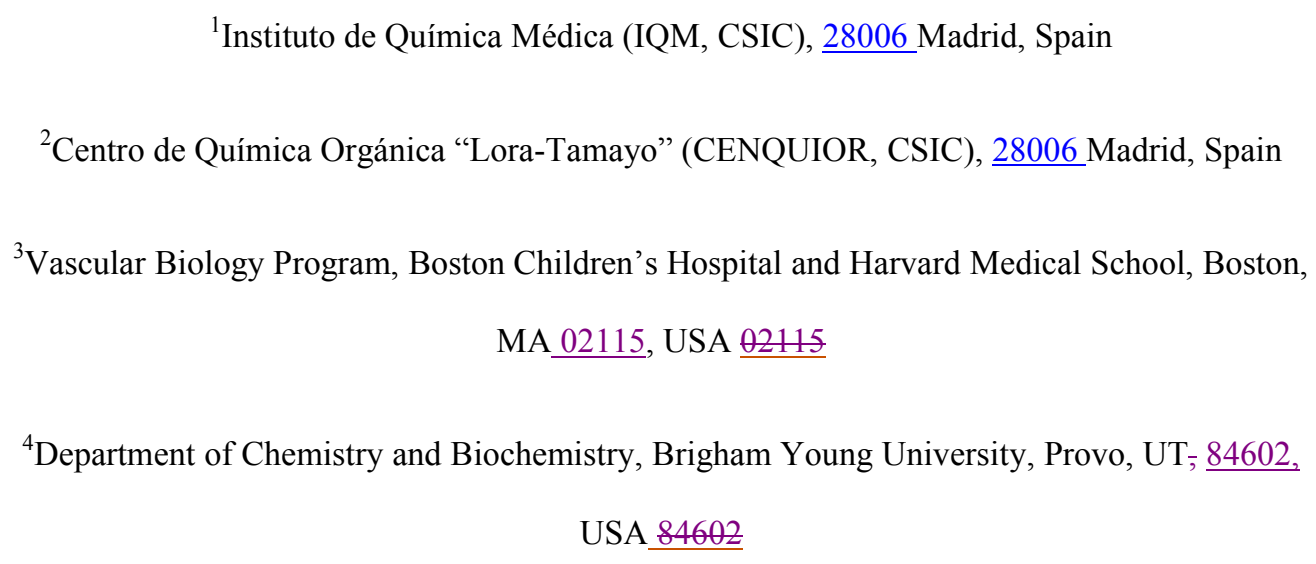

${ }^{3}$ Vascular Biology Program, Boston Children's Hospital and Harvard Medical School, Boston, MA $\underline{02115}$, USA $\underline{\theta 2115}$

${ }^{4}$ Department of Chemistry and Biochemistry, Brigham Young University, Provo, UT; $\underline{84602,}$ USA $\underline{84602}$

KEYWORDS. Angiogenesis; endothelial cells; CMG2; galloyl derivatives, carbohydrates 
ABSTRACT. We previously showed that a small molecule of natural origin, 1,2,3,4,6-penta- $O$ galloyl- $\beta$-D-glucopyranose (PGG), binds to Capillary Morphogenesis Gene 2 (CMG2) with a submicromolar $\mathrm{IC}_{50}$ and also has antiangiogenic activity in vitro and in vivo. In this work, we synthetized derivatives of PGG with different sugar cores and phenolic substituents and tested these as angiogenesis inhibitors. In a high-throughput FRET based binding assay we found that one of our synthetic analogs (PGM), with mannose as central core and galloyl substituents, exhibit higher (up to 10x) affinity for CMG2 than the natural glucose prototype PGG, and proved to be a potent angiogenesis inhibitor. These findings demonstrate that biochemical CMG2 binding in vitro predicts inhibition of endothelial cell migration ex vivo and antiangiogenic activity in vivo. The molecules herein described, and in particular PGM, might be useful prototypes for the development of novel agents for angiogenesis-dependent diseases, including blinding eye disease and cancer.

\section{Introduction}

Angiogenesis, the process by which new blood capillaries sprout from pre-existing vessels, is crucial for important physiological processes such as wound healing and reproduction ${ }^{1}$ but also for pathological processes such as cancer, arthritis, psoriasis, several rare genetic diseases and a variety of eye disorders, including macular degeneration among others. ${ }^{1-5}$ Thus, therapies that target angiogenesis can be effective in slowing or reversing the development of these diseases. ${ }^{6}$ As a result, anti-angiogenic therapy has received considerable attention and is widely administered in several types of human cancers and in blinding eye disease. ${ }^{7,8}$

Capillary Morphogenesis Gene 2 (CMG2) protein is a transmembrane receptor involved in angiogenesis and endothelial cell function. ${ }^{9,10}$ It also allows entry of anthrax toxin into host 
cells. ${ }^{11}$ In the context of the anthrax toxin it has been discovered that protective antigen (PA), one of the three monomeric proteins that composed anthrax toxin, binds with high affinity to CMG2 and orchestrates the delivery of the other two monomeric anthrax toxin subunits into the cytosol. ${ }^{11}$

We have previously shown that high-affinity CMG2 binders, like PA, can inhibit angiogenesis and tumor growth ${ }^{9,10}$ and described a high-throughput Förster resonant energy transfer (FRET) assay to identify CMG2-PA inhibitors. ${ }^{12}$ Using this assay, we demonstrated that a small molecule of natural origin, 1,2,3,4,6-penta-O-galloyl- $\beta$-D-glucopyranose (PGG, 1) (Figure 1), extracted from a tannic acid sample, binds to $\mathrm{CMG}_{2}$ with a submicromolar $\mathrm{IC}_{50}$ and also inhibits endothelial cell migration at similar concentration in vitro. ${ }^{13}$ In addition, oral or intraperitoneal administration of PGG inhibits angiogenesis in the mouse corneal micropocket assay in vivo. ${ }^{13}$ PGG is a natural polyphenol produced by a variety of medicinal plants that exhibits a variety of antitumor and other activities. ${ }^{13}$ Together these results indicate that at least a portion of the antitumor activity of PGG results from antiangiogenic activity mediated by binding with CMG2. In contrast, we found that methyl and propyl gallates and a number of additional polyphenols at concentrations up to $300 \mu \mathrm{M}$ do not showed any inhibitory activity. ${ }^{13}$ This result suggests the sugar core as a major contributor to the high-affinity CMG2 binding. 


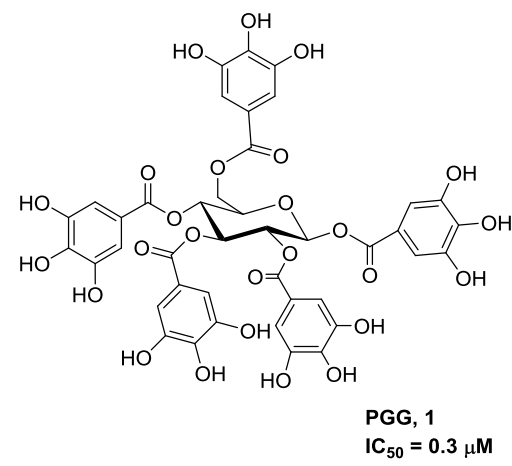

Figure 1. Previously reported $\beta$-D-glucose prototype (PGG)

The aim of the present work is to validate CMG2 binding in vitro as a predictor of antiendothelial activity ex vivo and antiangiogenic activity in vivo. Moreover, we sought to identify novel synthetic analogs of PGG with higher affinity for CMG2 and better antiangiogenic properties than the natural counterpart.

With this aim we decided to prepare and test as CMG2 inhibitors novel analogs of PGG (1), in which the glucose core is substituted by other monosaccharides (I) such as mannose, galactose or ribose, substituted with 5 or 4 trihydroxybenzoyl moieties respectively (Figure 2). Disaccharide derivatives (II), with 8 trihydroxybenzoyl moieties, were also prepared (Figure 2). Galloyl (3,4,5-trihydroxybenzoyl) and 2,3,4-trihydroxybenzoyl moieties were used as carbohydrate substituents in order to investigate the effect of the spatial distribution of the hydroxyl groups on the aromatic ring on activity.

The CMG2-PA inhibitory activity of these compounds was determined in vitro using the high throughput FRET assay developed in our group. ${ }^{12}$ For the best CMG2-PA inhibitor, the capacity to inhibit angiogenesis ex vivo and in vivo was also determined. 


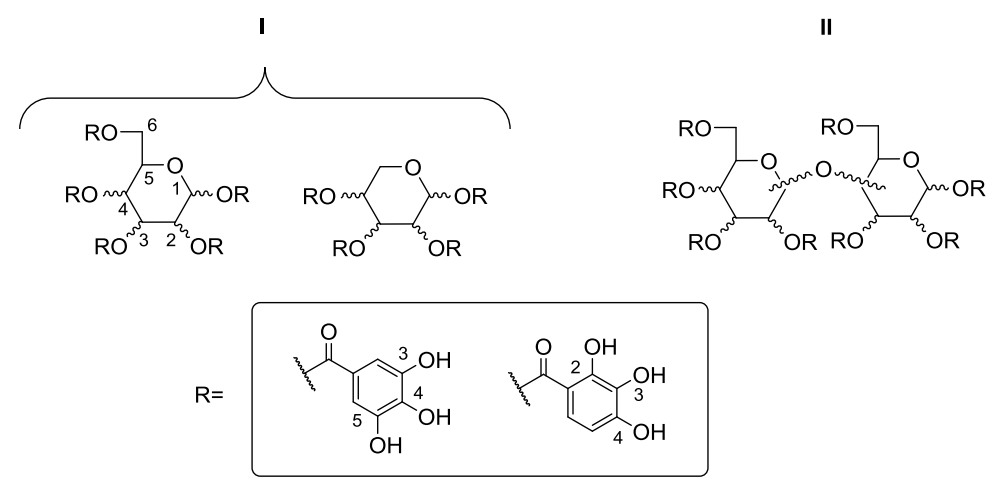

Figure 2. General structures of the proposed compounds

\section{Results and discussion}

\section{Chemical results}

First, synthesis of the gallic acid monosaccharide analogs (D-galactose, D-mannose and Dribose) of PGG (1) (Scheme 1) was undertaken. These compounds were prepared using the Steglich esterification protocol. ${ }^{14-17}$ Briefly, a solution of 3,4,5-tribenzyloxybenzoic acid $\mathbf{2}^{18-20}$ in acetonitrile was reacted with the appropriate carbohydrate in the presence of DCC as coupling reagent and DMAP as a base to give the corresponding OBn-protected derivatives: 3 (50\%), 5/6 $(90 \%)$ and $9(55 \%)$ in moderate to good yields. The basic conditions used in the reaction led to epimerization at $\mathrm{C}-1$ of the monosaccharide ring, with the epimerization degree depending of the reaction conditions and anomeric composition of the starting carbohydrate. Galactose and mannose yielded $\alpha, \beta$-anomeric mixtures, while the $\beta$-anomer was the major isomer when ribose was used. Separation of the protected $\alpha(5)$ and $\beta$ (6) mannose anomers were undertaken by 
column chromatography on silica gel using a mixture of dichloromethane:toluene:ethyl acetate in a ratio $75: 25: 1(\mathrm{v} / \mathrm{v} / \mathrm{v})$ as eluent. ${ }^{15,16}$ For galactose, the anomeric mixture 3 could not be separated.
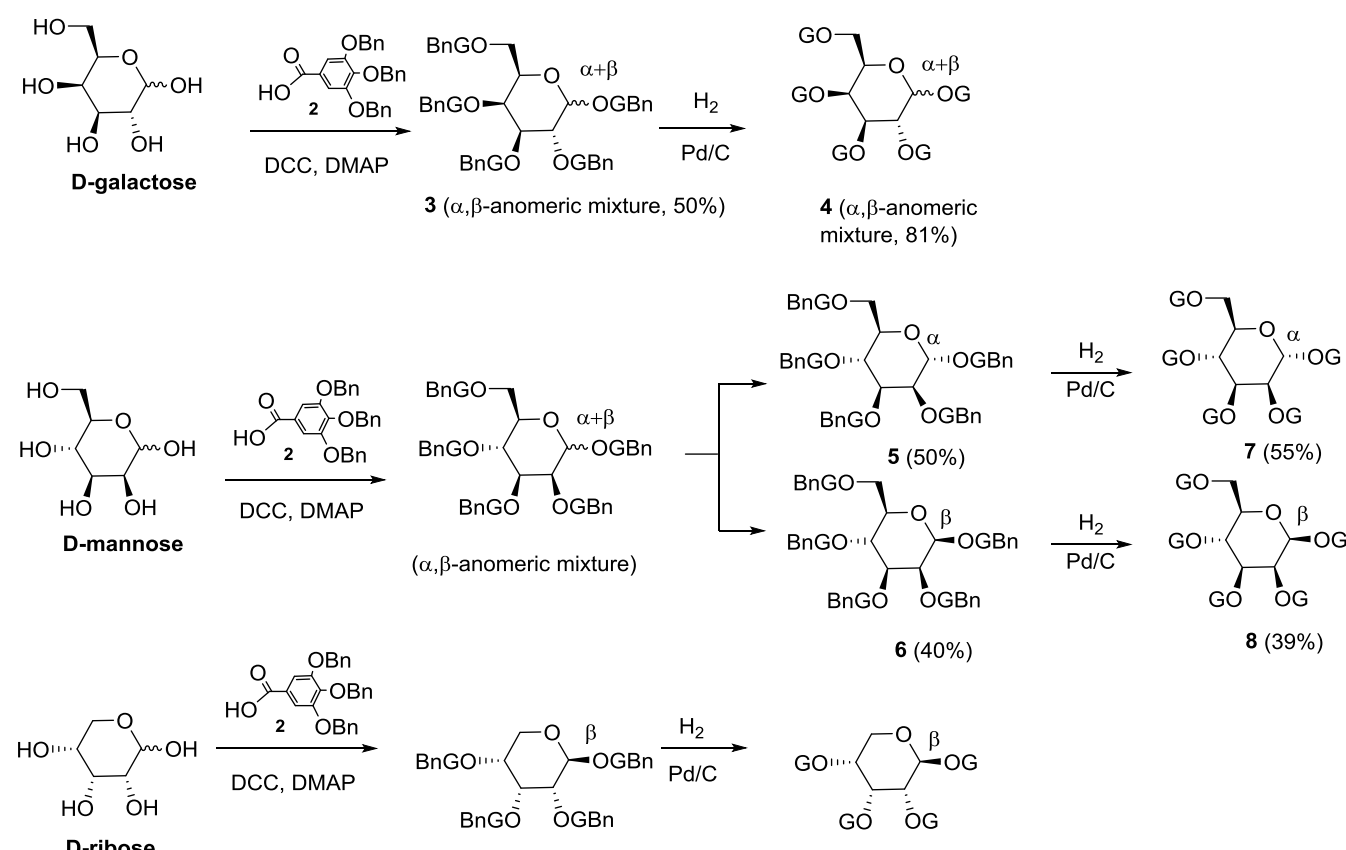

9 ( $\beta$-anomer, $55 \%)$

10 ( $\beta$-anomer, $40 \%)$

$\mathrm{BnG}=\mathrm{OBB}_{\mathrm{OBn}}^{\mathrm{OBn}}$

Scheme 1. Synthesis of the galloyl monosaccharide series 
Hydrogenolysis over $\mathrm{Pd} / \mathrm{C}$ of the Bn ether derivatives using the reported conditions ${ }^{15,16}$ (THF as solvent) gave intractable mixtures of partially deprotected compounds. However, when the hydrogenation reactions were performed in a mixture of THF and methanol (1:1) as solvent the deprotected final compounds $4,7,8$ and 10 were obtained in moderate to good yields.

In order to investigate the effect of the spatial distribution of the hydroxyl groups on the aromatic ring, the corresponding 2,3,4-trihydroxybenzoyl isomeric derivatives (Scheme 2) were also synthesized. In this case, the 2,3,4-benzyl protected phenol derivative 11, prepared according to literature procedures ${ }^{21}$ was employed as starting material. Condensation of $\mathbf{1 1}^{21}$ with the corresponding monosaccharides (D-glucose, D-galactose, D-mannose and D-ribose) was performed as in the gallic acid series. In most cases $\alpha / \beta$ mixtures were obtained. Chromatographic separation of the protected anomers followed by Bn deprotection afforded pure $\alpha$ and $\beta$ derivatives: 15 (93\%), 18 (78\%), 19 (80\%), 22 (40\%) and 23 (84\%). For glucose, anomeric separation was not possible and a mixture 1:2 of $\alpha: \beta$ anomers (13) was obtained in $57 \%$ yield. It should be mentioned that galactose derivative $\mathbf{1 5}$ was obtained in the furanose form (see Supplementary Material for additional information). 

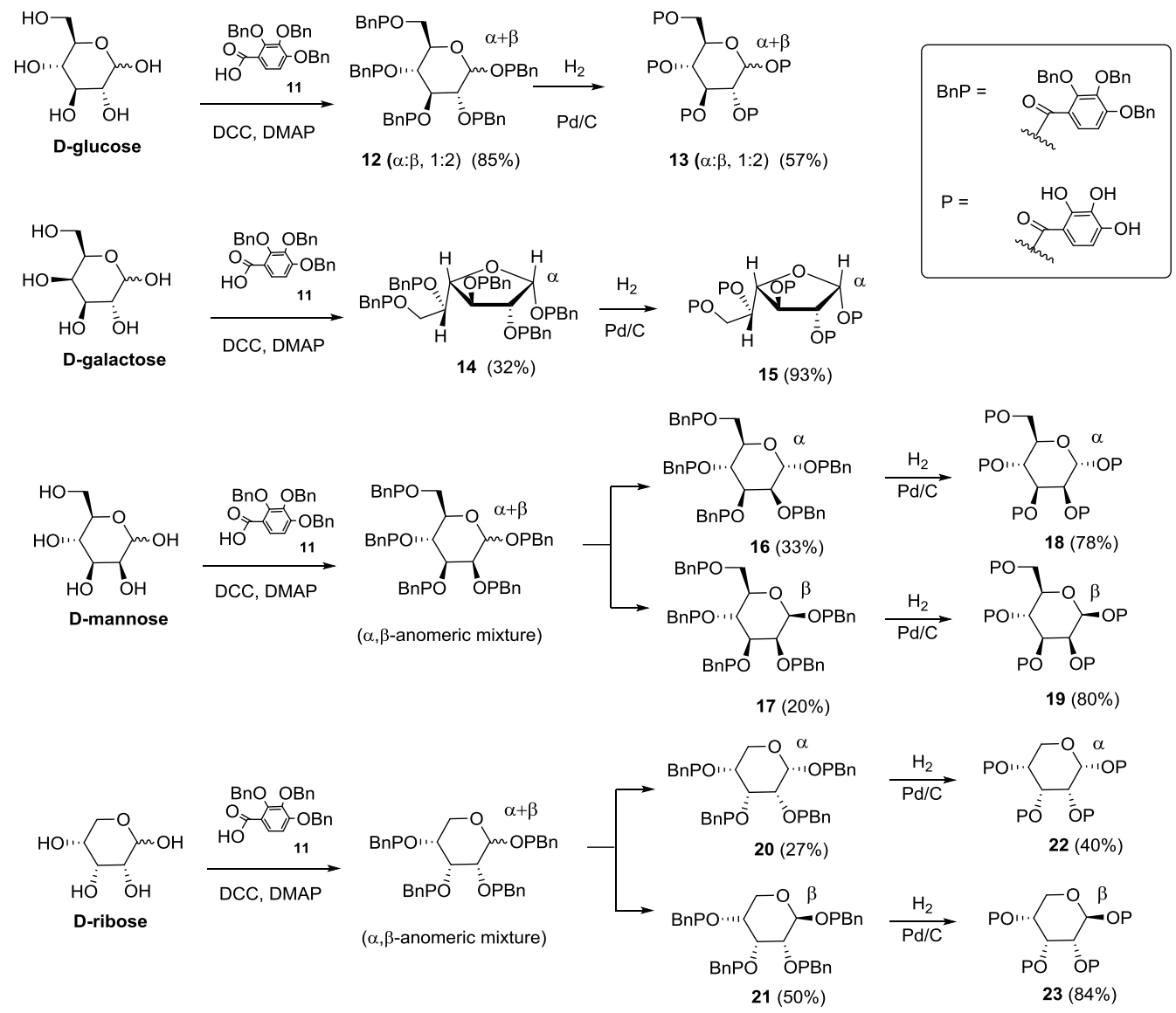

Scheme 2. Synthesis of the 2,3,4-trihydroxybenzoyl monosaccharide series

Next, disaccharide derivatives, with 8 galloyl or 2,3,4-trihydroxy benzoyl moieties, were prepared (Scheme 3). First, using a strategy similar to those described earlier for monosaccharides, maltose and $\alpha, \alpha$-trehalose were reacted with the benzyl gallic acid derivative $\mathbf{2}^{18-20}$ to give the corresponding OBn-protected derivatives $24(86 \%)$ and $26(81 \%)$ in good 
yields. Bn deprotection of these compounds afforded disaccharide derivatives 25 (82\%) and 27

$(80 \%)$ in good yields.

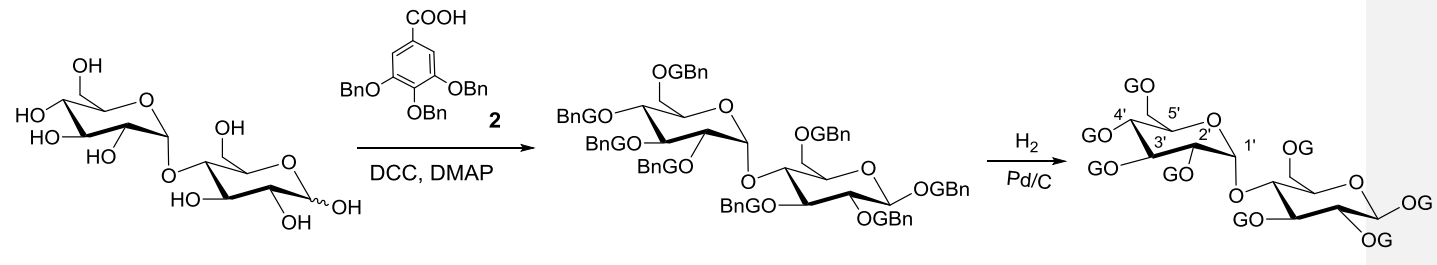

Maltose

$24(86 \%)$

$25(82 \%)$
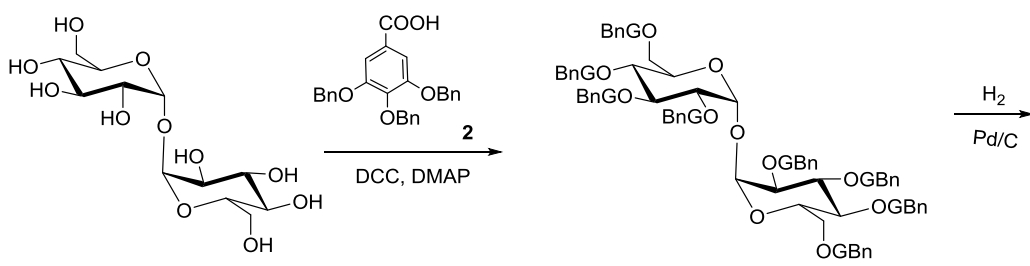

GO

$\alpha, \alpha$-Trehalose

$26(81 \%)$

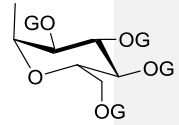

$27(80 \%)$

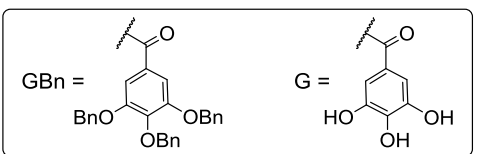

Scheme 3. Synthesis of the galloyl disaccharide series 
Finally, reaction of maltose and $\alpha, \alpha$-trehalose with the 2,3,4-benzyl trihydroxy benzoyl derivative $11^{21}$, followed by Bn deprotection gave pure disaccharide derivatives $\mathbf{2 9}$ and $\mathbf{3 1}$ in moderate yields (66\% and 54\%) respectively (Scheme 4).

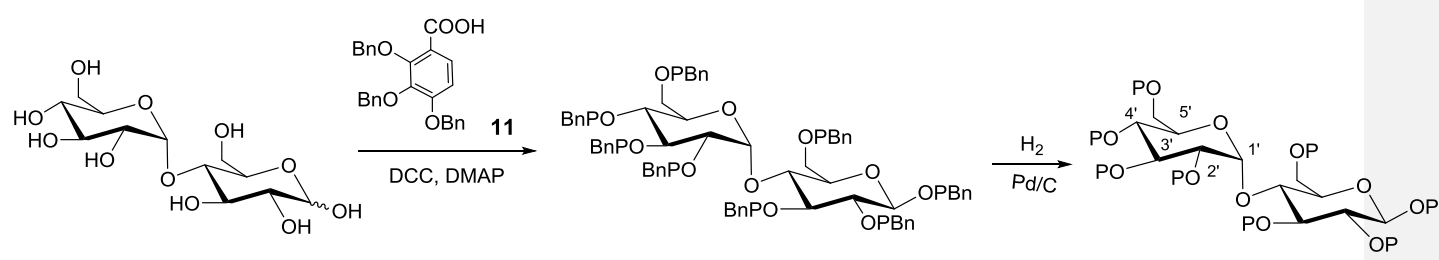

Maltose

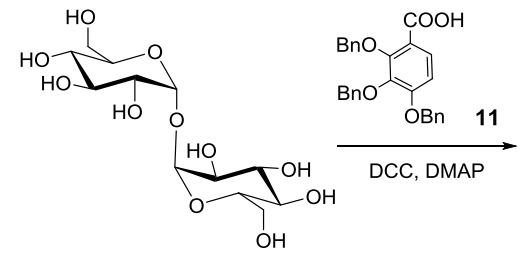

$\alpha, \alpha-$ Trehalose
$28(53 \%)$

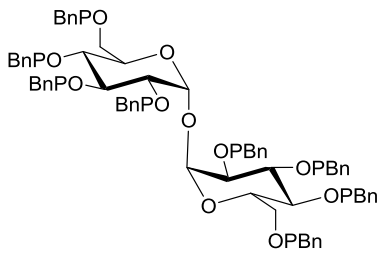

$30(79 \%)$

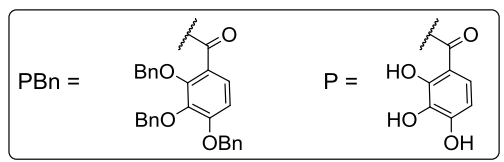

Scheme 4. Synthesis of the 2,3,4-trihydroxybenzoyl disaccharide series 
The structures of the novel carbohydrate derivatives were assigned by ${ }^{1} \mathrm{H}$ and ${ }^{13} \mathrm{C}$ NMR spectroscopic analysis. In the case of the galloyl monosaccharide derivatives 3-10, the spectroscopic data were identical to those reported previously. ${ }^{15,16}$ For the novel galloyl disaccharides and 2,3,4-trihydroxybenzoyl derivatives (mono- and disaccharides) well-known NMR rules, ${ }^{22,23}$ together with bidimensional NOESY and ROESY experiments and ${ }^{13} \mathrm{C}-{ }^{1} \mathrm{H}$ techniques $\left[\mathrm{gHMBC}^{24}\right.$ and $\mathrm{gHSQC}^{25}$ ] were applied for the unequivocal assignment of the structures (see Supplementary Material).

\section{Inhibition of CMG2}

Because the inhibition of CMG2-PA binding is predictive of inhibition of angiogenesis, each of these compounds was assessed for binding to CMG2 and inhibition of CMG2-PA binding using the FRET-based screening assay developed in our group ${ }^{12}$ (Table I). Interaction with CMG2 was also observed for many of these compounds in a bio-layer interferometry (BLI) assay, however long dissociation times led to imprecise estimations of binding affinity. Nevertheless, this result confirms interaction between CMG2 and PGG analogs. In the more precise FRET assay, we found that several compounds were stronger CMG2-PA inhibitors than is PGG. Specifically, we found that mannose derivatives $\mathbf{7 , ~ 8}$, and $\mathbf{1 9}$, showed better inhibitory effects than the glucose prototype, PGG (1). The galactose derivative 4 also showed better inhibitory effects than PGG, but it was not as potent as the previously mentioned mannose derivatives.

Table I. Inhibitory effects of test compounds with respect to PA-CMG2 inhibition ${ }^{\text {a }}$ 


\begin{tabular}{|c|c|c|c|c|}
\hline Compd. & Carbohydrate & Ring type & Benzoyl Substituent & $\mathrm{IC}_{50}(\mu \mathrm{M}, 95 \% \mathrm{CI})$ \\
\hline 4 & $\alpha / \beta$-galactose & pyranose & galloyl (G) & $0.167(0.095-0.293)$ \\
\hline 7 & $\alpha$-mannose & pyranose & galloyl (G) & $0.100(0.054-0.182)$ \\
\hline 8 & $\beta$-mannose & pyranose & galloyl (G) & $0.058(0.028-0.118)$ \\
\hline 10 & $\beta$-ribose & pyranose & galloyl (G) & $>10$ \\
\hline 13 & $\alpha / \beta$-glucose & pyranose & 2,3,4-trihydroxybenzoyl (P) & $3.420(1.980-5.907)$ \\
\hline 15 & $\alpha / \beta$-galactose & furanose & 2,3,4-trihydroxybenzoyl (P) & $>10$ \\
\hline 18 & $\alpha$-mannose & pyranose & 2,3,4-trihydroxybenzoyl (P) & $>10$ \\
\hline 19 & $\beta$-mannose & pyranose & 2,3,4-trihydroxybenzoyl (P) & $0.132(0.020-0.878)$ \\
\hline 22 & $\alpha$-ribose & pyranose & 2,3,4-trihydroxybenzoyl (P) & $>10$ \\
\hline 23 & $\beta$-ribose & pyranose & 2,3,4-trihydroxybenzoyl (P) & $>10$ \\
\hline 25 & maltose & pyranose & galloyl (G) & $>10$ \\
\hline 27 & $\alpha, \alpha$-trehalose & pyranose & galloyl (G) & $>10$ \\
\hline 29 & maltose & pyranose & 2,3,4-trihydroxybenzoyl (P) & $1.164(0.180-7.511)$ \\
\hline 31 & $\alpha, \alpha$-trehalose & pyranose & 2,3,4-trihydroxybenzoyl (P) & $>10$ \\
\hline $\begin{array}{c}1 \\
\text { (PGG) }\end{array}$ & $\beta$-glucose & pyranose & galloyl (G) & $607(0.348-1.058)$ \\
\hline
\end{tabular}

${ }^{\mathrm{a} C}$ Compounds were assessed for inhibition of PA-CMG2 interaction by FRET-based screening assay at 2-fold dilutions across a concentration range of 6 orders of magnitude, with $\mathrm{IC}_{50}$ determined by nonlinear fitting to the Hill equation.

The better inhibitory effects of mannose and galactose derivatives vs. glucose PGG, could be due to differences in the spatial orientation of the phenolic substituents (Figure 3). In the glucopyranose prototype PGG (1), all of the phenolic substituents adopt an "up" and "down" equatorial orientation on the pyranose ring, that is in chair conformation, while in mannose $(\mathbf{7}, \mathbf{8}$, 19) and galactose derivatives (4), one substituent either at C-2 (mannose) or C-4 (galactose) 
adopt an axial "up" orientation, that seems to increase the availability for interaction with CMG2.

Interestingly, the $\beta$-anomer of mannopyranose (8) resulted in better inhibition than its respective $\alpha$-anomer 7 . This key observation indicates that subtle structural differences have a significant impact on binding.

We also observed that galloyl (3,4,5-trihydroxybenzoyl) derivatives showed better inhibitory potency than the corresponding 2,3,4-trihydroxybenzoyl derivatives (compare $\mathbf{7}$ with $\mathbf{1 8}$ and $\mathbf{8}$ with 19). This observation suggests that the distribution of the phenolic $\mathrm{OH}$ groups around the aromatic ring is important for the $\mathrm{CMG} 2$ binding.
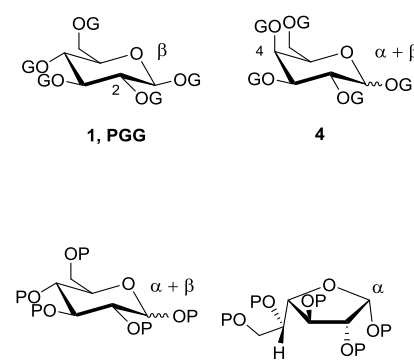

13
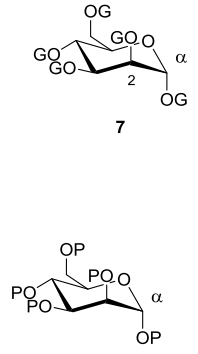

18
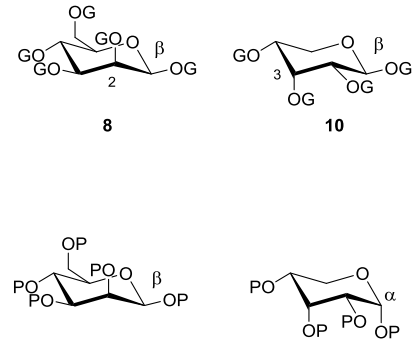

19

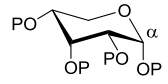

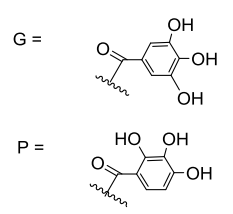

22

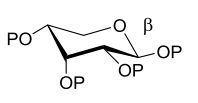

23

Figure 3. Differences in the spatial orientation of the phenolic substituents 
The $\alpha(\mathbf{2 2})$ and $\beta(\mathbf{1 0}, \mathbf{2 3})$ ribose derivatives, with one galloyl group less than the glucose prototype 1, showed no inhibitory effect. The lack of inhibitory effects of these compounds, particularly of compound $\mathbf{2 3}$, with a $\beta$ configuration, as in the glucose prototype $\mathbf{1}$, suggests that at least five galloyl groups are required for optimal binding, with the galloyl group at C-6 position (present in $\mathbf{1}$ but not in the ribose derivatives 10, 22 or 23 ) being particularly important. It should also be noted that in the ribose derivatives $(\mathbf{1 0}, \mathbf{2 2}$ and $\mathbf{2 3})$ the phenolic substituent at $\mathrm{C}$ 3 adopts an axial "down" orientation contrary to the equatorial "up" orientation that this substituent adopts in the glucose prototype $\mathbf{1}$. This might also account for the lack of inhibitory effects showed by the ribose derivatives.

With the exception of maltose derivative 29, all disaccharides $(\mathbf{2 5}, 27$ and 31$)$, with 8 phenolic substituents, did not inhibit CMG2-PA interaction showing that extra aromatic substituents are not necessary and that five phenolic residues are enough for binding.

\section{Inhibition of angiogenesis ex vivo and in vivo}

We next sought evidence that the mannose derivative (8, PGM), that showed the highest affinity for $\mathrm{CMG} 2$, can also inhibit endothelial cell migration and angiogenesis. To assess antimigratory activity, we used EA.hy926 cells, which are an immortal Human umbilical vein endothelial cell (HUVEC)-A549 hybrid with endothelial cell characteristics. In a microfluidic chamber, migration of these cells toward serum was monitored by video microscopy. Treatment with PGM resulted in a dose-dependent inhibition of migration with potency in a nanomolar range (Figure 4) $\left(\mathrm{IC}_{50}: 400 \mathrm{nM}\right.$ ), over two-fold better than those observed for the prototype PGG $\left(\mathrm{IC}_{50}: 830 \mathrm{nM}\right)^{5}$ 
Finally, because angiogenesis can only be definitively analyzed in living animals, we turned to the corneal micropocket assay. We assessed the inhibitory activity of the mannose derivative $\mathbf{8}$ (PGM) against basic fibroblast growth factor (bFGF)-driven angiogenesis by treating mice intraperitoneally with a dose of $10 \mathrm{mg} / \mathrm{kg}$ of the compound. Importantly, when compared to vehicle-treated control animals, no significant weight loss was observed (i.e. the compound was not overtly toxic). Consistent with the anti-endothelial activity observed in cell culture, PGMtreated animals consistently exhibited a significant decrease in vessel area of $\sim 20 \%$. Together, these data demonstrate that PGM is well tolerated and effectively inhibits angiogenesis ex vitro and in vivo.
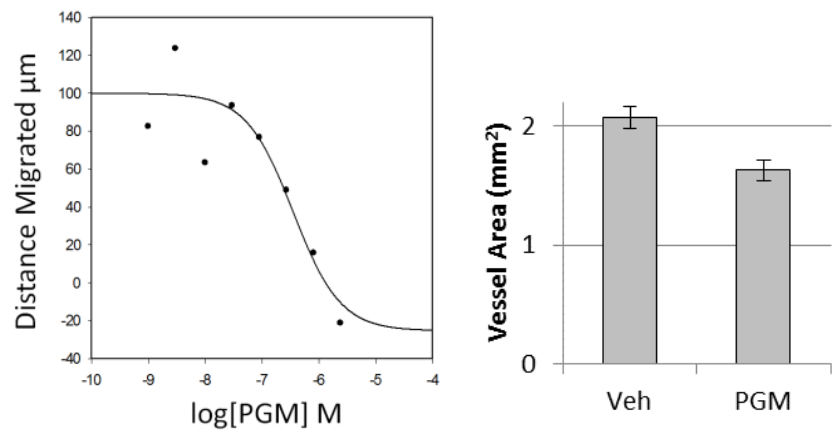

Figure 4. PGM activity ex vivo and in vivo. Left. PGM inhibits chemotactic endothelial cell migration up a $0 \%$ to $10 \%$ serum gradient. Ea.hy926 cells were grown on prepared imaging chambers and then treated with PGM for $12 \mathrm{~h}$. Cell migration was monitored by time lapse transmitted light microscopy and position tracked in analysis software. Migration distance is the Euclidian distance each cell migrated toward the serum gradient $(\mathrm{n}=40)$. Best fit $\mathrm{IC}_{50}=365 \pm$ 129. Right. PGM inhibits bFGF-induced angiogenesis in the corneal micropocket assay. Mice 
were implanted with $80 \mathrm{ng}$ bFGF pellets and treated with $10 \mathrm{mg} / \mathrm{kg} / \mathrm{day}$ of PGM. Difference is significant $(\mathrm{P}<0.01$ by t-test, Veh $\mathrm{n}=9$, PGM $\mathrm{n}=10)$.

\section{Conclusions}

Novel synthetic analogs of 1,2,3,4,6-glucopyranose- $O$-galloyl- $\beta$-D-glucopyranose (PGG) with different sugar cores (glucose, galactose, mannose, ribose, trehalose and maltose) and phenolic substituents (galloyl and 2,3,4-trihydroxybenzoyl) have been synthesized and tested as CMG2 inhibitors. These compounds were prepared from commercially available carbohydrates in three steps (OBn phenolic OHs protection-carbohydrate/phenolic acid coupling-OBn deprotection). Attempts to conduct the final deprotection step in pure methanol failed, giving intractable mixtures of uncompleted deprotected compounds. However, mixtures of THF/methanol $(1: 1)$ gave the corresponding phenol-deprotected derivatives in very good yields.

Structure-activity trends can be identified in this series, notwithstanding the strong similarity of some of these compounds-many differ only at the stereochemistry of a few atoms. We observed that galloyl moieties confer higher CMG2 binding than its corresponding 2,3,4trihydroxybenzoyl isomer and that the mannose and galactose galloyl derivatives exhibit higher (up to 10x) affinity for CMG2 than the glucose prototype PGG in the FRET based binding assay. This result demonstrates that, as it was anticipated from previous work, the sugar core is an important structural element for CMG2 binding, probably because it allows that the galloyl groups adopt the optimal spatial orientation to interact properly with CMG2. This strongly indicates that a specific interaction with $\mathrm{CMG} 2$, rather than a general disruption of protein structure or metal chelation, underlies inhibition by these polyphenol derivatives. 
The mannose derivative 8 (PGM), that showed the highest affinity for CMG2, can also inhibit endothelial cell migration and angiogenesis. All of these findings demonstrate that biochemical CMG2 inhibition in vitro is a good predictor of antiendothelial activity ex vivo and antiangiogenic activity in vivo. Importantly, we observed no obvious signs of toxicity (weight loss, hunched posture, behavioral abnormalities), indicating that the reduction in angiogenic response is a result of a pharmacologic effect of $\mathbf{8}$ rather than general animal toxicity.

Accordingly, these results indicate that the molecules herein described, an in particular the most potent mannose derivative $\mathbf{8}$, might be useful prototypes for the development of novel CMG2-PA inhibitors and antiangiogenic agents.

\section{Experimental Section}

\section{Synthesis}

\section{General chemical procedures}

Commercial reagents and solvents were used as received from the suppliers without further purification unless otherwise stated. Dichloromethane was dried prior to use by distillation from $\mathrm{CaH}_{2}$ and stored over Linde type activated $4 \AA$ molecular sieves.

Analytical thin-layer chromatography (TLC) was performed on aluminium plates pre-coated with silica gel $60\left(\mathrm{~F}_{254}, 0.25 \mathrm{~mm}\right)$. Products were visualized using an ultraviolet lamp (254 nm and $365 \mathrm{~nm}$ ) or by heating on a hot plate (approx. $200{ }^{\circ} \mathrm{C}$ ), directly or after treatment with a $5 \%$ solution of phosphomolybdic acid or vanillin in ethanol.

The compounds were purified by: a) flash column chromatography on silica gel (60 Merck 
230-400 mesh), b) trituration with dichloromethane or methanol/ dichloromethane.

For HPLC analysis was used an Alliance 2695 (Waters) equipped with a PDA (Photo Diode Array) detector Waters 2996. Acetonitrile was used as mobile phase A with $0.08 \%$ of formic acid, and water was used as mobile phase B with $0.1 \%$ of formic acid at a flow rate of $1 \mathrm{~mL} \cdot \mathrm{min}^{-}$

1. Two different methods were used, one on a XBridge $C_{18}(2.1 \times 100 \mathrm{~mm}, 3.5 \mu \mathrm{m})$ column with $5-80 \%$ of $\mathrm{A}$, that will be noted as $t_{R(X)}$, and the other on a SunFire $\mathrm{C}_{18}(4.6 \times 50 \mathrm{~mm}, 3.5 \mu \mathrm{m})$ column with $0-100 \%$ of $\mathrm{A}$, that will be noted as $t_{R(S)}$. All retention times are quoted in minutes.

Melting points were measured on a Reichert-Jung Kofler and are uncorrected.

NMR spectra $\left({ }^{1} \mathrm{H},{ }^{13} \mathrm{C} \mathrm{NMR}\right)$ were recorded on a $300 \mathrm{MHz}$ (Varian Inova 300), $400 \mathrm{MHz}$ (Varian Inova 400) and $500 \mathrm{MHz}$ (Varian System 500) spectrometers, using $\mathrm{CDCl}_{3},\left(\mathrm{CD}_{3}\right)_{2} \mathrm{CO}$, $\left(\mathrm{CD}_{3}\right)_{2} \mathrm{SO}$ and $\mathrm{CD}_{3} \mathrm{OD}$ as solvents at room temperature. Chemical shift $(\delta)$ values are reported in parts per million (ppm) relative to tetramethylsilane (TMS) in ${ }^{1} \mathrm{H}$ and $\mathrm{CDCl}_{3}(\delta=77.0)$ in ${ }^{13} \mathrm{C}$ NMR. Coupling constant ( $J$ values) are reported in hertz $(\mathrm{Hz})$, and multiplicities of signals are indicated by the following symbol: s (singlet), d (doublet), $\mathrm{t}$ (triplet), q (quartet), m (multiplet).

Mass spectra were registered in a quadrupole mass spectrometer 1100 Hewlett Packard equipped with an electrospray source.

The purity of the final compounds was at least $95 \%$ as determined by microanalyses with a Heraeus CHN-O-RAPID instrument. Analyses indicated by the symbols of the elements or functions were within $\pm 0.4 \%$ of the theorical values.

Final compounds were lyophilized using a Telstar 6-80 system.

\section{General carbohydrate esterification method}

A suspension of the corresponding sugar derivative $(1 \mathrm{eq})$, the benzoic acid $\mathbf{2}^{18-20}$ or $\mathbf{1 1}{ }^{21}(7.5$ eq), DCC (8 eq) and DMAP (8 eq) in dry dichloromethane $(70 \mathrm{~mL})$ was refluxed under argon 
overnight. After the mixture was cooled to room temperature, the urea byproduct was filtered through celite and the filtrate was evaporated. The residue was purified by column chromatography or precipitation. For disaccharides (maltose and $\alpha, \alpha$-trehalose) 11.2 eq of the benzoic acid $\mathbf{2}^{18-20}$ or $\mathbf{1 1},{ }^{21}$ DCC (12.8 eq) and DMAP (12.8 eq) were used.

\section{General procedure for Bn group deprotection}

A solution of the corresponding OBn protected derivative $(1 \mathrm{mmol})$ in $\mathrm{THF} /$ methanol $(1: 1)$ $(100 \mathrm{~mL})$ containing $30 \mathrm{wt} \%$ of $\mathrm{Pd} / \mathrm{C}(10 \%)$ was hydrogenated at $2.85 \mathrm{~atm}(42 \mathrm{psi})$ at $30{ }^{\circ} \mathrm{C}$ overnight. The $\mathrm{Pd} / \mathrm{C}$ was filtered through Whatman ${ }^{\circledR}$ filter paper 42 and the solvent was removed under reduced pressure to give the corresponding deprotected derivatives as unique products.

\section{Galloyl monosaccharide series (3-10)}

Melting points and characterization of the benzyl protected galloyl intermediates 3, 5, 6 and 9 and their corresponding deprotected derivatives $4,7,8$ and 10 were consistent with those found

in the literature. ${ }^{15,16}$ In our case, the following yields were obtained: $3(50 \%), 4(81 \%), 5(50 \%)$, $6(40 \%), 7(55 \%), 8(39 \%), 9(55 \%)$, and $10(40 \%)$.

\section{$\alpha$ and $\beta$-D-Glucopiranose pentakis[2,3,4-tris(phenylmethoxy)benzoate] (12)}

Following the general carbohydrate esterification method, a solution of D-glucose (50 mg, $0.28 \mathrm{mmol})$ in dry dichloromethane $(70 \mathrm{~mL})$ was treated with 2,3,4-tribenzyloxybenzoic acid $\mathbf{1 1}^{21}$ (915 mg, 2.08 mmoles, 7.5 eq), DCC (454 mg, $2.22 \mathrm{mmol}, 8$ eq) and DMAP (270 mg, 2.22 mmol, 8 eq). The residue was purified by column chromatography using toluene/ethyl acetate 
20:1 as eluent to give $545.3 \mathrm{mg}$ ( $85 \%$ ) of $\mathbf{1 2}(\alpha$ and $\beta$ anomers, $1: 2)$ as an amorphous white solid. ${ }^{1} \mathrm{H}-\mathrm{NMR}\left[\mathrm{CDCl}_{3}, 400 \mathrm{MHz}\right] \delta$ 3.81-3.88 (m, 1H), 4.40-4.62 (m, 3H), 4.70-5.22 (m, 30H, O-CH $2-\mathrm{Ph}), 5.63-5.92(\mathrm{~m}, 3 \mathrm{H}), 6.09(\mathrm{~d}, J=7.3 \mathrm{~Hz}, 1 \mathrm{H}), 6.20-6.30(\mathrm{~m}, 1 \mathrm{H}), 6.36(\mathrm{~d}, J=9.1 \mathrm{~Hz}$, $1 \mathrm{H}), 6.46(\mathrm{t}, J=9.9 \mathrm{~Hz}, 1 \mathrm{H}), 6.55(\mathrm{t}, J=8.3 \mathrm{~Hz}, 1 \mathrm{H}), 6.70-6.80(\mathrm{~m}, 1 \mathrm{H}), 6.80-6.90(\mathrm{~m}, 1 \mathrm{H})$, 7.18-7.97 (m, 79H, H-Ar). ${ }^{13} \mathrm{C}-\mathrm{NMR}\left[\mathrm{CDCl}_{3}, 100 \mathrm{MHz}\right] \delta 61.21\left(\mathrm{CH}_{2}\right), 61.45\left(\mathrm{CH}_{2}\right), 67.30$ $(\mathrm{CH}), 67.47(\mathrm{CH}), 68.82(\mathrm{CH}), 69.01(\mathrm{CH}), 69.23(\mathrm{CH}), 69.52(\mathrm{CH}), 69.56\left(\mathrm{CH}_{2}\right), 69.59\left(\mathrm{CH}_{2}\right)$, $69.66\left(\mathrm{CH}_{2}\right), 69.69\left(\mathrm{CH}_{2}\right), 69.90\left(\mathrm{CH}_{2}\right), 71.29(\mathrm{CH}), 72.04(\mathrm{CH}), 74.37\left(\mathrm{CH}_{2}\right), 74.41\left(\mathrm{CH}_{2}\right)$, $74.42\left(\mathrm{CH}_{2}\right), 74.44\left(\mathrm{CH}_{2}\right), 74.48\left(\mathrm{CH}_{2}\right), 74.53\left(\mathrm{CH}_{2}\right), 74.61\left(\mathrm{CH}_{2}\right), 74.91\left(\mathrm{CH}_{2}\right), 74.99\left(\mathrm{CH}_{2}\right)$, $75.03\left(\mathrm{CH}_{2}\right), 75.06\left(\mathrm{CH}_{2}\right), 75.14\left(\mathrm{CH}_{2}\right), 75.19\left(\mathrm{CH}_{2}\right), 75.24\left(\mathrm{CH}_{2}\right), 75.28\left(\mathrm{CH}_{2}\right), 75.34\left(\mathrm{CH}_{2}\right)$, $75.80\left(\mathrm{CH}_{2}\right), 88.87(\mathrm{CH}), 91.20(\mathrm{CH}), 107.44(\mathrm{CH}), 107.52(\mathrm{CH}), 107.58(\mathrm{CH}), 107.62(\mathrm{CH})$, $107.65(\mathrm{CH}), 107.67(\mathrm{CH}), 107.76(\mathrm{CH}), 115.24(\mathrm{C}), 115.58(\mathrm{C}), 115.65(\mathrm{C}), 115.72(\mathrm{C}), 115.76$ (C), $115.87(\mathrm{C}), 116.41(\mathrm{C}), 117.15(\mathrm{C}), 117.23(\mathrm{C}), 126.37(\mathrm{CH}), 126.43(\mathrm{CH}), 126.45(\mathrm{CH})$, $126.49(\mathrm{CH}), 126.59(\mathrm{CH}), 126.71(\mathrm{CH}), 126.78(\mathrm{CH}), 126.85(\mathrm{CH}), 126.90(\mathrm{CH}), 126.93(\mathrm{CH})$, $126.96(\mathrm{CH}), 126.99(\mathrm{CH}), 127.02(\mathrm{CH}), 127.09(\mathrm{CH}), 127.11(\mathrm{CH}), 127.13(\mathrm{CH}), 127.15(\mathrm{CH})$, 127.18(CH), $127.20(\mathrm{CH}), 127.23(\mathrm{CH}), 127.25(\mathrm{CH}), 127.28(\mathrm{CH}), 127.31(\mathrm{CH}), 127.34(\mathrm{CH})$, $127.36(\mathrm{CH}), 127.50(\mathrm{CH}), 127.53(\mathrm{CH}), 127.55(\mathrm{CH}), 127.60(\mathrm{CH}), 127.63(\mathrm{CH}), 127.67(\mathrm{CH})$, $127.68(\mathrm{CH}), 127.71(\mathrm{CH}), 127.74(\mathrm{CH}), 127.75(\mathrm{CH}), 127.79(\mathrm{CH}), 127.92(\mathrm{CH}), 127.65(\mathrm{CH})$, $127.38(\mathrm{CH}), 128.01(\mathrm{CH}), 128.05(\mathrm{CH}), 134.96(\mathrm{C}), 134.98(\mathrm{C}), 135.01(\mathrm{C}), 135.02(\mathrm{C}), 135.05$ (C), 135.22 (C), 135.99 (C), 136.12 (C), 136.15 (C), 136.18 (C), 136.23 (C), 136.30 (C), 136.31 (C), 136.34 (C), 136.36 (C), 136.40 (C), 136.42 (C), 136.52 (C), 136.55 (C), 136.67 (C), 141.35 (C), 141.39 (C), 141.45 (C), 141.46 (C), 141.53 (C), 141.55 (C), 141.77 (C), 153.04 (C), 153.09 (C), 153.38 (C), 153.44 (C), 153.54 (C), 153.58 (C), 153.73 (C), 153.77 (C), 155.58 (C), 155.62 (C), 155.84 (C), 155.88 (C), 155.90 (C), 156.01 (C), 156.12 (C), 156.19 (C), 160.91 (C=O), 
$161.22(\mathrm{C}=\mathrm{O}), 161.86(\mathrm{C}=\mathrm{O}), 161.93(\mathrm{C}=\mathrm{O}), 162.12(\mathrm{C}=\mathrm{O}), 162.30(\mathrm{C}=\mathrm{O}), 162.32(\mathrm{C}=\mathrm{O})$, $162.54(\mathrm{C}=\mathrm{O}), 163.28(\mathrm{C}=\mathrm{O}), 163.37(\mathrm{C}=\mathrm{O}) . \mathrm{HRMS}(\mathrm{ES}+): \mathrm{m} / \mathrm{z}$ calculated: 2290.8224 ; found: $2309.8652\left(\mathrm{M}+\mathrm{NH}_{4}\right),{ }^{+} 2314.8309(\mathrm{M}+\mathrm{Na}){ }^{+}$

\section{$\alpha$ and $\beta$-D-Glucopiranose pentakis(2,3,4-trihydroxybenzoate) (13)}

According to the general procedure for the deprotection of benzyl ethers, the mixture of $\alpha$ and $\beta$ anomers 12 (100 $\mathrm{mg}, 0.046 \mathrm{mmol}$ ) was hydrogenated, to give $43 \mathrm{mg}$ of a yellow oil that was triturated with dichloromethane, to give $24.6 \mathrm{mg}$ (57\%) of $\mathbf{1 3}$ ( $\alpha$ and $\beta$ anomers, $1: 2$ ) as a dark yellow solid. The peaks in ${ }^{1} \mathrm{H}$ NMR were assigned from the mixture of anomers using bidimensional experiments. The peaks in ${ }^{13} \mathrm{C}$ NMR correspond to the $\alpha$ and $\beta$ mixture.

Anomer $\beta:{ }^{1} \mathrm{H}-\mathrm{NMR}\left[\mathrm{CD}_{3} \mathrm{OD}, 400 \mathrm{MHz}\right] \delta 4.50-4.70(\mathrm{~m}, 3 \mathrm{H}, \mathrm{H}-5, \mathrm{H}-6), 5.75(\mathrm{t}, J=9.0 \mathrm{~Hz}$, 2H, H-2, H-4), 6.08 (t, $J=9.63 \mathrm{~Hz}, 1 \mathrm{H}, \mathrm{H}-3$ ), 6.30-6.43 (m, 6H, H-1, H-Ar), 7.20-7.39 (m, 5H, H-Ar).

Anomer $\alpha:{ }^{1} \mathrm{H}-\mathrm{NMR}\left[\mathrm{CD}_{3} \mathrm{OD}, 400 \mathrm{MHz}\right] \delta$ 4.50-4.70 (m, 3H, H-5, H-6), 5.70 (dd, $9.92 \mathrm{~Hz}, J$ $=3.70 \mathrm{~Hz}, 1 \mathrm{H}, \mathrm{H}-2), 5.82(\mathrm{t}, J=9.92 \mathrm{~Hz}, 1 \mathrm{H}, \mathrm{H}-4), 6.20(\mathrm{t}, J=9.92 \mathrm{~Hz}, 1 \mathrm{H}, \mathrm{H}-3), 6.22(\mathrm{~d}, J=$ $8.78 \mathrm{~Hz}, 1 \mathrm{H}, \mathrm{H}-\mathrm{Ar}), 6.30-6.43$ (m, 3H, H-Ar), 6.58 (d, $J=8.66 \mathrm{~Hz}, 1 \mathrm{H}, \mathrm{H}-\mathrm{Ar}), 6.85$ (d, $J=3.70$ Hz, 1H, H-1), 7.02 (d, $J=8.88 \mathrm{~Hz}, 1 \mathrm{H}, \mathrm{H}-\mathrm{Ar}), 7.20-7.39$ (m, 3H, H-Ar), 7.60 (d, $J=9.31 \mathrm{~Hz}$, $1 \mathrm{H}, \mathrm{H}-\mathrm{Ar})$.

(Anomer $\alpha$ and $\beta$, mixture 1:2): ${ }^{13} \mathrm{C}-\mathrm{NMR}\left[\mathrm{CD}_{3} \mathrm{OD}, 100 \mathrm{MHz}\right] \delta 63.89\left(\mathrm{CH}_{2}\right), 64.09\left(\mathrm{CH}_{2}\right)$, $70.17(\mathrm{CH}), 70.75(\mathrm{CH}), 71.95(\mathrm{CH}), 72.12(\mathrm{CH}), 72.23(\mathrm{CH}), 72.45(\mathrm{CH}), 74.20(\mathrm{CH}), 74.28$ (CH), $91.76(\mathrm{CH}), 93.97$ (CH), 105.17 (C), 105.31 (C), 105.33 (C), 105.47 (C), 106.12 (C), $109.14(\mathrm{CH}), 109.40(\mathrm{CH}), 109.61(\mathrm{CH}), 123.20(\mathrm{CH}), 123.37(\mathrm{CH}), 123.57(\mathrm{CH}), 130.69(\mathrm{C})$, 133.95 (C), 134.06 (C), 134.08 (C), 134.10 (C), 134.25 (C), 134.46 (C), 152.72 (C), 152.82 (C), 
152.91 (C), 153.15 (C), 153.25 (C), 153.44 (C), 153.47 (C), 153.91 (C), 154.02 (C), 154.04 (C), $154.05(\mathrm{C}), 154.35(\mathrm{C}), 154.42(\mathrm{C}), 169.96(\mathrm{C}=\mathrm{O}), 170.55(\mathrm{C}=\mathrm{O}), 170.60(\mathrm{C}=\mathrm{O}), 170.63(\mathrm{C}=\mathrm{O})$, $170.83(\mathrm{C}=\mathrm{O}), 171.06(\mathrm{C}=\mathrm{O}), 171.48(\mathrm{C}=\mathrm{O}) . \mathrm{MS}(\mathrm{ES}+): \mathrm{m} / \mathrm{z} 963.0(\mathrm{M}+\mathrm{Na})^{+}, 771.2(\mathrm{M}-169$, corresponding to the loss of 2,3,4-trihydroxybenzoate) ${ }^{+}$. Anal. calculated for $\mathrm{C}_{41} \mathrm{H}_{32} \mathrm{O}_{26}$ : C, 52.35; H, 3.43. Found: C, 52.16; H, 3.71.

\section{$\alpha-D-G a l a c t o f u r a n o s e ~ p e n t a k i s[2,3,4-t r i s(p h e n y l m e t h o x y) b e n z o a t e] ~(14)$}

Following the general carbohydrate esterification method, a solution of D-galactose (50 mg, $0.28 \mathrm{mmol})$ in dry dichloromethane $(70 \mathrm{~mL})$ was treated with 2,3,4-tribenzyloxybenzoic acid $\mathbf{1 1}^{21}$ (915 mg, 2.08 mmoles, 7.5 eq), DCC (454 mg, $\left.2.22 \mathrm{mmol}, 8 \mathrm{eq}\right)$ and DMAP (270 mg, 2.22 mmol, 8 eq). The residue was purified by column chromatography using toluene/ethyl acetate 20:1 as eluent to give $200 \mathrm{mg}$ ( $32 \%$ ) of $\mathbf{1 4}$ ( $\alpha$ anomer) as a white solid. Anomer $\beta$ was not detected. ${ }^{1} \mathrm{H}-\mathrm{NMR}\left[\mathrm{CDCl}_{3}, 300 \mathrm{MHz}\right] \delta$ 4.76-4.92 (m, 3H), 4.98-5.45 (m, 35H), 5.93-6.00 (m, 1H), 6.08-6.15 (m, 1H), $6.35(\mathrm{~d}, J=8.3 \mathrm{~Hz}, 1 \mathrm{H}), 6.43-6.53(\mathrm{~m}, 2 \mathrm{H}), 6.66-6.76(\mathrm{~m}, 2 \mathrm{H}), 6.86(\mathrm{~d}$, $J=10.8 \mathrm{~Hz}, 1 \mathrm{H}), 7.05(\mathrm{~d}, J=4.7 \mathrm{~Hz}, 1 \mathrm{H}), 7.31-7.61(\mathrm{~m}, 57 \mathrm{H}), 7.63-7.66(\mathrm{~m}, 3 \mathrm{H}), 7.68-7.74(\mathrm{~m}$, 7H, H-Ar), 7.75-7.81 (m, 4H, H-Ar), 7.84-7.97 (m, 4H, H-Ar).

\section{$\alpha-D-G a l a c t o f u r a n o s e ~ p e n t a k i s(2,3,4-t r i h y d r o x y b e n z o a t e)(15)$}

Following the general deprotection procedure, the benzyl protected derivative 14 (57 mg, 0.03 mmol) gave $43 \mathrm{mg}$ of a yellow oil that was precipitated using a mixture of methanol and dichloromethane to give $21.9 \mathrm{mg}(93 \%)$ of $\mathbf{1 5}$ as a white solid. m.p. $177-179^{\circ} \mathrm{C} .[\alpha]^{20}{ }_{\mathrm{D}}+75.7(\mathrm{c}$ $\left.1.40, \mathrm{CD}_{3} \mathrm{OD}\right) ;{ }^{1} \mathrm{H}-\mathrm{NMR}\left[\mathrm{CD}_{3} \mathrm{OD}, 400 \mathrm{MHz}\right] \delta 4.65(\mathrm{dd}, J=6.20 \mathrm{~Hz}, J=12.44 \mathrm{~Hz}, 1 \mathrm{H}, \mathrm{H}-6 \mathrm{~A})$, 4.79-4.85 (m, 2H, H-4, H-6B), 5.85 (ddd, $J=6.20 \mathrm{~Hz}, J=3.35 \mathrm{~Hz}, J=5.29 \mathrm{~Hz}, 1 \mathrm{H}, \mathrm{H}-5$ ), 5.94 
(dd, $J=6.98 \mathrm{~Hz}, J=4.88 \mathrm{~Hz}, 1 \mathrm{H}, \mathrm{H}-2), 6.10$ (d, $J=9.24 \mathrm{~Hz}, 1 \mathrm{H}, \mathrm{H}-\mathrm{Ar}), 6.21$ (d, $J=9.24 \mathrm{~Hz}$, 1H, H-Ar), 6.26 (t, $J=6.38 \mathrm{~Hz}, 1 \mathrm{H}, \mathrm{H}-3$ ), 6.30 (d, $J=9.07 \mathrm{~Hz}, 1 \mathrm{H}, \mathrm{H}-\mathrm{Ar}), 6.33$ (d, $J=9.03 \mathrm{~Hz}$, 1H, H-Ar), 6.36 (d, $J=9.24 \mathrm{~Hz}, 1 \mathrm{H}, \mathrm{H}-\mathrm{Ar}), 6.80$ (d, $J=5.09 \mathrm{~Hz}, 1 \mathrm{H}, \mathrm{H}-1), 7.17$ (d, $J=8.45 \mathrm{~Hz}$, 1H, H-Ar), 7.19 (d, $J=9.31 \mathrm{~Hz}, 1 \mathrm{H}, \mathrm{H}-\mathrm{Ar}$ ), 7.22 (d, $J=8.96 \mathrm{~Hz}, 1 \mathrm{H}, \mathrm{H}-\mathrm{Ar}$ ), 7.26 (d, $J=9.03$ $\mathrm{Hz}, 1 \mathrm{H}, \mathrm{H}-\mathrm{Ar}), 7.33$ (d, $J=9.03 \mathrm{~Hz}, 1 \mathrm{H}, \mathrm{H}-\mathrm{Ar}) .{ }^{13} \mathrm{C}-\mathrm{NMR}\left[\mathrm{CD}_{3} \mathrm{OD}, 100 \mathrm{MHz}\right] \delta 63.95\left(\mathrm{CH}_{2}\right)$, $71.60(\mathrm{CH}), 75.47(\mathrm{CH}), 77.38(\mathrm{CH}), 80.68(\mathrm{CH}), 95.85(\mathrm{CH}), 104.86(\mathrm{C}), 105.06(\mathrm{C}), 105.19$ (C), $105.31(\mathrm{C}), 105.64(\mathrm{C}), 108.73(\mathrm{CH}), 108.86(\mathrm{CH}), 108.95(\mathrm{CH}), 122.56(\mathrm{CH}), 122.72(\mathrm{CH})$ , 122.88 (CH), 133.58 (C), 133.60 (C), 133.65 (C), 133.68 (C), 152.29 (C), 152.35 (C), 152.43 (C), 152.57 (C), 152.92 (C), 153.12 (C), 153.45 (C), 153.49 (C), 170.15 (C=O), 170.25 (C=O), $170.60(\mathrm{C}=\mathrm{O}), 170.65(\mathrm{C}=\mathrm{O}), 171.09(\mathrm{C}=\mathrm{O}) . \operatorname{HRMS}\left(\mathrm{ES}^{-}\right): \mathrm{m} / \mathrm{z}$ calculated: 940.118181182; found: 939.10936 $\underline{1094}(\mathrm{M}-\mathrm{H})^{-}$. Anal. Calculated for $\mathrm{C}_{41} \mathrm{H}_{32} \mathrm{O}_{26}$ : C, 52.35; H, 3.43. Found: $\mathrm{C}$, 51.99; H, 3.29 .

\section{$\alpha$ - and $\beta$-D-Mannopyranose pentakis[2,3,4-tris(phenylmethoxy)benzoate] (16 and 17)}

Following the general carbohydrate esterification method, a solution of D-mannose (50 mg, $0.28 \mathrm{mmol})$ in dry dichloromethane $(70 \mathrm{~mL})$ was treated with $\mathbf{1 1}^{21}(915 \mathrm{mg}, 2.08$ mmoles, 7.5 eq), DCC (454 mg, $2.22 \mathrm{mmol}, 8 \mathrm{eq})$ and DMAP (270 mg, $2.22 \mathrm{mmol}, 8 \mathrm{eq})$ to give a residue that was purified by column chromatography on silica gel using a mixture of toluene/ethyl acetate (96:4). From the fastest running fraction $203 \mathrm{mg}$ (33\%) of $\mathbf{1 6}$ ( $\alpha$ anomer) was obtained as an amorphous white solid. ${ }^{1} \mathrm{H}$ NMR $\left(\mathrm{CDCl}_{3}, 300 \mathrm{MHz}\right) \delta$ : 4.41-4.50 (m, 2H, H-6), 4.65 (bd, $1 \mathrm{H}$, H-5), 4.85-5.29 (m, 30H, CH $2-\mathrm{Ph}), 5.91$ (m, 1H, H-2), 6.09 (dd, $J=3.0 \mathrm{~Hz}, J=10.2 \mathrm{~Hz}, 1 \mathrm{H}, \mathrm{H}-$ 3), $6.20(\mathrm{t}, J=10.1 \mathrm{~Hz}, 1 \mathrm{H}, \mathrm{H}-4), 6.40(\mathrm{~d}, J=9.1 \mathrm{~Hz}, 1 \mathrm{H}, \mathrm{H}-\mathrm{Ar}), 6.55-6.61$ (m, 4H, H-Ar and H1), 6.84 (d, $J=8.9 \mathrm{~Hz}, 1 \mathrm{H}, \mathrm{H}-\mathrm{Ar}), 6.90$ (d, $J=9.1 \mathrm{~Hz}, 1 \mathrm{H}, \mathrm{H}-\mathrm{Ar}), 7.19-7.70$ (m, 77H, H-Ar), 
$7.80(\mathrm{~d}, J=8.9 \mathrm{~Hz}, 1 \mathrm{H}, \mathrm{H}-\mathrm{Ar}), 7.87$ (d, $J=8.9 \mathrm{~Hz}, 1 \mathrm{H}, \mathrm{H}-\mathrm{Ar}) .{ }^{13} \mathrm{C}-\mathrm{NMR}\left[\mathrm{CDCl}_{3}, 100 \mathrm{MHz}\right] \delta$ $62.34\left(\mathrm{CH}_{2}\right), 66.22(\mathrm{CH}), 69.27(\mathrm{CH}), 69.36(\mathrm{CH}), 70.57\left(\mathrm{CH}_{2}\right), 70.75\left(\mathrm{CH}_{2}\right), 70.80\left(\mathrm{CH}_{2}\right)$, $70.89\left(\mathrm{CH}_{2}\right), 70.91\left(\mathrm{CH}_{2}\right), 70.97\left(\mathrm{CH}_{2}\right), 71.37(\mathrm{CH}), 75.45\left(\mathrm{CH}_{2}\right), 75.50\left(\mathrm{CH}_{2}\right), 75.57\left(\mathrm{CH}_{2}\right)$, $75.63\left(\mathrm{CH}_{2}\right), 75.68\left(\mathrm{CH}_{2}\right), 76.01\left(\mathrm{CH}_{2}\right), 76.26\left(\mathrm{CH}_{2}\right), 76.30\left(\mathrm{CH}_{2}\right), 76.37\left(\mathrm{CH}_{2}\right), 91.03(\mathrm{CH})$, $108.54(\mathrm{CH}), 108.62(\mathrm{CH}), 108.80(\mathrm{CH}), 108.89(\mathrm{CH}), 116.93(\mathrm{C}), 117.21(\mathrm{C}), 117.24(\mathrm{C})$, $117.50(\mathrm{C}), 118.58(\mathrm{C}), 127.20(\mathrm{CH}), 127.39(\mathrm{CH}), 127.42(\mathrm{CH}), 127.50(\mathrm{CH}), 127.52(\mathrm{CH})$, $127.56(\mathrm{CH}), 127.58(\mathrm{CH}), 127.62(\mathrm{CH}), 127.65(\mathrm{CH}), 127.80(\mathrm{CH}), 127.85(\mathrm{CH}), 127.92(\mathrm{CH})$, $127.95(\mathrm{CH}), 127.99(\mathrm{CH}), 128.07(\mathrm{CH}), 128.08(\mathrm{CH}), 128.11(\mathrm{CH}), 128.14(\mathrm{CH}), 128.17(\mathrm{CH})$, $128.22(\mathrm{CH}), 128.24(\mathrm{CH}), 128.30(\mathrm{CH}), 128.34(\mathrm{CH}), 128.46(\mathrm{CH}), 128.48(\mathrm{CH}), 128.50(\mathrm{CH})$, $128.54(\mathrm{CH}), 128.56(\mathrm{CH}), 128.61(\mathrm{CH}), 128.64(\mathrm{CH}), 128.73(\mathrm{CH}), 128.75(\mathrm{CH}), 128.78(\mathrm{CH})$, $128.82(\mathrm{CH}), 128.92(\mathrm{CH}), 128.96(\mathrm{CH}), 129.04(\mathrm{CH}), 129.09(\mathrm{CH}), 135.95(\mathrm{C}), 135.97(\mathrm{C})$, 136.06 (C), 136.08 (C), 136.22 (C), 137.02 (C), 137.04 (C), 137.15 (C), 137.17 (C), 137.24 (C), 137.29 (C), 137.30 (C), 137.43 (C), 137.47 (C), 142.42 (C), 142.47 (C), 142.52 (C), 142.66 (C), 142.79 (C), 154.06 (C), 154.32 (C), 154.52 (C), 154.70 (C), 156.46 (C), 156.61 (C), 156.89 (C), $156.98(\mathrm{C}), 157.06(\mathrm{C}), 157.41(\mathrm{C}), 161.80(\mathrm{C}=\mathrm{O}), 162.92(\mathrm{C}=\mathrm{O}), 163.23(\mathrm{C}=\mathrm{O}), 163.63(\mathrm{C}=\mathrm{O})$, $164.25(\mathrm{C}=\mathrm{O})$.

From the slowest running fraction $124.2 \mathrm{mg}(20 \%)$ of 17 ( $\beta$ anomer) was obtained as a white solid. Mp 188-190 ${ }^{\circ} \mathrm{C} .\left(\mathrm{CDCl}_{3}, 300 \mathrm{MHz}\right) \delta$ : 4.49-4.68 (m, 3H, H-5, H-6), 4.82-5.17 (m, 30H, $\mathrm{CH}_{2}-\mathrm{Ph}$ ), 5.71 (dd, $\left.J=3.2 \mathrm{~Hz}, J=10.0 \mathrm{~Hz}, 1 \mathrm{H}, \mathrm{H}-3\right), 6.03$ (t, $\left.J=10.0 \mathrm{~Hz}, 1 \mathrm{H}, \mathrm{H}-4\right), 6.09$ (d, $J=$ $3.2 \mathrm{~Hz}, 1 \mathrm{H}, \mathrm{H}-2), 6.23$ (s, 1H, H-1), 6.40 (dd, $J=2.3 \mathrm{~Hz}, J=9.0 \mathrm{~Hz}, \mathrm{H}-\mathrm{Ar}), 6.55$ (d, $J=8.9 \mathrm{~Hz}$, 1H, H-Ar), 6.62 (dd, $J=1.2 \mathrm{~Hz}, J=9.0 \mathrm{~Hz}, 2 \mathrm{H}, \mathrm{H}-\mathrm{Ar}), 7.20-7.68$ (m, 78H, H-Ar), 7.80 (d, $J=$ $8.9 \mathrm{~Hz}, 1 \mathrm{H}, \mathrm{H}-\mathrm{Ar}), 7.86$ (d, $J=8.9 \mathrm{~Hz}, 1 \mathrm{H}, \mathrm{H}-\mathrm{Ar})$. 


\section{a-D-Mannopyranose pentakis(2,3,4-trihydroxybenzoate) (18)}

Following the general deprotection procedure, the benzyl protected derivative 16 (200 $\mathrm{mg}$, $0.08 \mathrm{mmol})$ gave $63.6 \mathrm{mg}$ (78\% yield) of the deprotected $\alpha$ anomer 18 as a white solid. Mp 158$160{ }^{\circ} \mathrm{C} .[\alpha]^{24}+4.0^{\circ}$ (c 0.15 , acetone). HPLC: $t_{R(S)}=3.58 \mathrm{~min} .{ }^{1} \mathrm{H}$ NMR $\left(\mathrm{CD}_{3} \mathrm{OD}, 400 \mathrm{MHz}\right) \delta$ : 4.52-4.68 (m, 3H, H-5 and H-6), $5.93(\mathrm{dd}, J=2.0 \mathrm{~Hz}, J=3.2 \mathrm{~Hz}, \mathrm{H}-2), 5.98(\mathrm{dd}, J=3.2 \mathrm{~Hz}, J=$ $10.2 \mathrm{~Hz}, 1 \mathrm{H}, \mathrm{H}-3), 6.16$ (t, $J=10.1 \mathrm{~Hz}, 1 \mathrm{H}, \mathrm{H}-4), 6.20$ (d, $J=8.9 \mathrm{~Hz}, 1 \mathrm{H}, \mathrm{H}-\mathrm{Ar}), 6.35$ (d, $J=8.9$ Hz, 1H, H-Ar), 6.38 (d, $J=8.8 \mathrm{~Hz}, 1 \mathrm{H}, \mathrm{H}-\mathrm{Ar}), 6.45$ (d, $J=8.8 \mathrm{~Hz}, 1 \mathrm{H}, \mathrm{H}-\mathrm{Ar}), 6.56$ (d, $J=8.8$ Hz, 1H, H-Ar), 6.57 (d, J=1.9 Hz, 1H, H-1), 6.95 (d, J=8.9 Hz, 1H, H-Ar), 7.32 (d, $J=8.9 \mathrm{~Hz}$, 1H, H-Ar), 7.39 (d, $J=8.8 \mathrm{~Hz}, 1 \mathrm{H}, \mathrm{H}-\mathrm{Ar}), 7.46$ (d, $J=8.8 \mathrm{~Hz}, 1 \mathrm{H}, \mathrm{H}-\mathrm{Ar}), 7.57$ (d, $J=8.8 \mathrm{~Hz}$, 1H, H-Ar). ${ }^{13} \mathrm{C}$ NMR $\left(\mathrm{CD}_{3} \mathrm{OD}, 100 \mathrm{MHz}\right) \delta: 62.69\left(\mathrm{CH}_{2}\right), 66.60(\mathrm{CH}), 70.27(\mathrm{CH}), 71.35(\mathrm{CH})$, $72.44(\mathrm{CH}), 92.65(\mathrm{CH}), 105.00(\mathrm{C}), 105.02$ (C), $105.06(\mathrm{C}), 105.11(\mathrm{C}), 105.84$ (C), 108.88 (CH), $108.94(\mathrm{CH}), 109.28(\mathrm{CH}), 109.31(\mathrm{CH}), 122.39(\mathrm{CH}), 122.44(\mathrm{CH}), 122.48(\mathrm{CH}), 122.61$ (CH), $122.85(\mathrm{CH}), 133.51(\mathrm{C}), 133.60(\mathrm{C}), 133.72(\mathrm{C}), 133.81(\mathrm{C}), 133.95(\mathrm{C}), 152.25(\mathrm{C})$, 152.36 (C), 152.40 (C), 152.59 (C), 152.80 (C), 152.89 (C), 153.23 (C), 153.39 (C), 153.49 (C), $153.84(\mathrm{C}), 168.91(\mathrm{C}=\mathrm{O}), 169.95(\mathrm{C}=\mathrm{O}), 170.22(\mathrm{C}=\mathrm{O}), 170.28(\mathrm{C}=\mathrm{O}), 170.88(\mathrm{C}=\mathrm{O})$. MS $(\mathrm{ES}+) \mathrm{m} / z: 941(\mathrm{M}+\mathrm{H})^{+}, 771.7(\mathrm{M}-169 \text {, corresponding to the loss of 2,3,4-trihydroxybenzoate })^{+}$. Anal. Calcd. for $\mathrm{C}_{41} \mathrm{H}_{32} \mathrm{O}_{26}:$ C, 52.35; H, 3.43. Found: C, 52.08; H, 3.71.

\section{ß-D-Mannopyranose pentakis(2,3,4-trihydroxybenzoate) (19)}

Following the general deprotection procedure the benzyl protected derivative 17 (100 mg, $0.044 \mathrm{mmol})$ gave $33.2 \mathrm{mg}(80 \%$ ) of the deprotected $\beta$ anomer 19 as a white solid. Mp 160-162 ${ }^{\circ} \mathrm{C} .[\alpha]^{24}+79.9^{\circ}$ (c 0.154 , acetone). HPLC: $t_{R(S)}=3.50 \mathrm{~min} .{ }^{1} \mathrm{H}$ NMR $\left(\mathrm{CD}_{3} \mathrm{OD}, 400 \mathrm{MHz}\right) \delta$ : $4.49(\mathrm{dt}, J=3.0 \mathrm{~Hz}, J=9.8 \mathrm{~Hz}, 1 \mathrm{H}, \mathrm{H}-5), 4.62(\mathrm{dd}, J=3.0 \mathrm{~Hz}, J=12.5 \mathrm{~Hz}, 1 \mathrm{H}, \mathrm{H}-6 \mathrm{~A}), 4.71$ 
(dd, $J=2.5 \mathrm{~Hz}, J=12.5 \mathrm{~Hz}, 1 \mathrm{H}, \mathrm{H}-6 \mathrm{~B}), 5.92(\mathrm{dd}, J=3.2 \mathrm{~Hz}, J=9.9 \mathrm{~Hz}, 1 \mathrm{H}, \mathrm{H}-3), 6.05$ (t, $J=$ $9.9 \mathrm{~Hz}, 1 \mathrm{H}, \mathrm{H}-4), 6.08$ (dd, $J=1.0 \mathrm{~Hz}, J=3.2 \mathrm{~Hz}, 1 \mathrm{H}, \mathrm{H}-2$ ), 6.22 (d, $J=8.9 \mathrm{~Hz}, \mathrm{H}-\mathrm{Ar}$ ), 6.25 (d, $J=8.9 \mathrm{~Hz}, 1 \mathrm{H}, \mathrm{H}-\mathrm{Ar}), 6.37$ (d, $J=8.9 \mathrm{~Hz}, 1 \mathrm{H}, \mathrm{H}-\mathrm{Ar}), 6.41$ (d, $J=8.8 \mathrm{~Hz}, 1 \mathrm{H}, \mathrm{H}-\mathrm{Ar}), 6.46$ (d, $J$ $=8.8 \mathrm{~Hz}, 1 \mathrm{H}, \mathrm{H}-\mathrm{Ar}), 6.53(\mathrm{~d}, J=1.1 \mathrm{~Hz}, 1 \mathrm{H}, \mathrm{H}-1), 6.99$ (d, $J=9.8 \mathrm{~Hz}, 1 \mathrm{H}, \mathrm{H}-\mathrm{Ar}), 7.01$ (d, $J=$ $9.8 \mathrm{~Hz}, 1 \mathrm{H}, \mathrm{H}-\mathrm{Ar}$ ), 7.31 (d, $J=7.3 \mathrm{~Hz}, 1 \mathrm{H}, \mathrm{H}-\mathrm{Ar}), 7.48$ (d, $J=8.3 \mathrm{~Hz}, 1 \mathrm{H}, \mathrm{H}-\mathrm{Ar}$ ), 7.49 (d, $J=$ $8.3 \mathrm{~Hz}, 1 \mathrm{H}, \mathrm{H}-\mathrm{Ar}) .{ }^{13} \mathrm{C} \mathrm{NMR}\left(\mathrm{CD}_{3} \mathrm{OD}, 100 \mathrm{MHz}\right) \delta: 62.98\left(\mathrm{CH}_{2}\right), 67.25(\mathrm{CH}), 70.72(\mathrm{CH})$, $72.47(\mathrm{CH}), 73.90(\mathrm{CH}), 92.13(\mathrm{CH}), 104.80(\mathrm{C}), 104.98(\mathrm{C}), 105.11(\mathrm{C}), 105.20(\mathrm{C}), 105.84$ (C), $108.86(\mathrm{CH}), 108.99(\mathrm{CH}), 109.26(\mathrm{CH}), 122.43(\mathrm{CH}), 122.57(\mathrm{CH}), 122.63(\mathrm{CH}), 133.51$ (C), 133.60 (C), 133.66 (C), 133.72 (C), 133.82 (C), 152.28 (C), 152.34 (C), 152.43 (C), 152.53 (C), 152.62 (C), 152.88 (C), 153.26 (C), 153.38 (C), 153.46 (C), 153.60 (C), 168.95 (C=O), $170.13(\mathrm{C}=\mathrm{O}), 170.26(\mathrm{C}=\mathrm{O}), 170.55(\mathrm{C}=\mathrm{O}), 170.90(\mathrm{C}=\mathrm{O}) . \quad \mathrm{EM}(\mathrm{ES}+) m / z: 941(\mathrm{M}+\mathrm{H})^{+}, 771.7$ (M-169, corresponding to the loss of 2,3,4-trihydroxybenzoate) ${ }^{+}$. Anal. Calcd. for $\mathrm{C}_{41} \mathrm{H}_{32} \mathrm{O}_{26}: \mathrm{C}$, 52.35; H, 3.43. Found: C, 52.07; H, 3.71.

\section{$\alpha$ and $\beta$-D-Ribopiranose tetrakis[2,3,4-tris(phenylmethoxy)benzoate] (20 and 21)}

Following the general carbohydrate esterification method, a solution of D-ribose ( $75 \mathrm{mg}, 0.5$ $\mathrm{mmol})$ in dry dichloromethane $(70 \mathrm{~mL})$ was treated with $\mathbf{1 1}^{21}(1.23 \mathrm{~g}, 2.8$ mmoles, $7.5 \mathrm{eq})$, DCC (660 mg, $3.2 \mathrm{mmol}, 8 \mathrm{eq}$ ) and DMAP (391 mg, $3.2 \mathrm{mmol}, 8 \mathrm{eq})$ to give a residue that was purified by column chromatography using hexane/ethyl acetate (4:1) and then toluene/ethyl acetate (40:1) as solvents.

From the slowest running fraction $254 \mathrm{mg}$ (27\%) of $\mathbf{2 0}$ ( $\alpha$ anomer) was obtained as a white solid. M.p. $62-64{ }^{\circ} \mathrm{C} .[\alpha]^{20}{ }_{\mathrm{D}}+20.6\left(\mathrm{c} 0.30, \mathrm{CH}_{2} \mathrm{Cl}_{2}\right) ;{ }^{1} \mathrm{H}-\mathrm{NMR}\left[\mathrm{CDCl}_{3}, 400 \mathrm{MHz}\right] \delta$ : 3.95-4.10 (m, 2H), $4.33(\mathrm{t}, J=9.7 \mathrm{~Hz} 1 \mathrm{H}), 4.90-5.20\left(\mathrm{~m}, 24 \mathrm{H}, \mathrm{O}-\mathrm{CH}_{2}-\mathrm{Ph}\right), 5.50-5.62(\mathrm{~m}, 1 \mathrm{H}), 5.63-5.75$ 
(m, 1H), $6.24(\mathrm{~d}, J=8.6 \mathrm{~Hz}, 1 \mathrm{H}), 6.34(\mathrm{~d}, J=8.6 \mathrm{~Hz}, 1 \mathrm{H}), 6.44(\mathrm{~d}, J=9.1 \mathrm{~Hz}, 2 \mathrm{H}), 6.60-6.76$ (m, 1H), 7.10-7.62 (m, 63H, H-Ar), $7.70(\mathrm{~d}, J=8.1 \mathrm{~Hz}, 1 \mathrm{H}, \mathrm{H}-\mathrm{Ar}) \cdot{ }^{13} \mathrm{C}-\mathrm{NMR}\left[\mathrm{CDCl}_{3}, 100\right.$ MHz] $\delta 66.25(\mathrm{CH}), 67.12(\mathrm{CH}), 67.74(\mathrm{CH}), 70.59\left(\mathrm{CH}_{2}\right), 70.73\left(\mathrm{CH}_{2}\right), 70.87\left(\mathrm{CH}_{2}\right), 70.98$ $\left(\mathrm{CH}_{2}\right), \quad 75.54\left(\mathrm{CH}_{2}\right), 75.55\left(\mathrm{CH}_{2}\right), 75.58\left(\mathrm{CH}_{2}\right), 76.35\left(\mathrm{CH}_{2}\right), 76.44\left(\mathrm{CH}_{2}\right), 76.47\left(\mathrm{CH}_{2}\right), 9.07$ $(\mathrm{CH}), 108.28(\mathrm{CH}), 108.32(\mathrm{CH}), 108.35(\mathrm{CH}), 108.57(\mathrm{CH}), 117.20(\mathrm{C}), 117.62(\mathrm{C}), 118.13$ (C), $127.44(\mathrm{CH}), 127.46(\mathrm{CH}), 127.52(\mathrm{CH}), 127.55(\mathrm{CH}), 127.60(\mathrm{CH}), 127.99(\mathrm{CH}), 128.04$ $(\mathrm{CH}), 128.06(\mathrm{CH}), 128.10(\mathrm{CH}), 128.19(\mathrm{CH}), 128.24(\mathrm{CH}), 128.28(\mathrm{CH}), 128.30(\mathrm{CH}), 128.33$ $(\mathrm{CH}), 128.38(\mathrm{CH}), 128.43(\mathrm{CH}), 128.54(\mathrm{CH}), 128.57(\mathrm{CH}), 128.59(\mathrm{CH}), 128.66(\mathrm{CH}), 128.68$ $(\mathrm{CH}), 128.71(\mathrm{CH}), 128.85(\mathrm{CH}), 128.90(\mathrm{CH}), 128.96(\mathrm{CH}), 129.03(\mathrm{CH}), 135.74(\mathrm{C}), 135.78$ (C), 136.01 (C), 136.97 (C), 137.13 (C), 137.18 (C), 137.27 (C), 142.50 (C), 142.55 (C), 142.61 (C), 142.64 (C), 154.23 (C), 154.41 (C), 154.48 (C), 154.62 (C), 156.67 (C), 156.81 (C), 156.85 (C), $162.90(\mathrm{C}=\mathrm{O}), 162.98(\mathrm{C}=\mathrm{O}), 163.42(\mathrm{C}=\mathrm{O}), 163.58(\mathrm{C}=\mathrm{O})$. HRMS(ES+): $m / z$ calculated: 1838.6601; found: $1857.6908\left(\mathrm{M}+\mathrm{NH}_{4}\right),{ }^{+} 1862.6466(\mathrm{M}+\mathrm{Na}){ }^{+}$Anal. Calcd. for $\mathrm{C}_{117} \mathrm{H}_{98} \mathrm{O}_{21}: \mathrm{C}$, 76.37; H, 5.37. Found: C, 76.65; H, 5.21.

From the fastest running fraction $461 \mathrm{mg}(50 \%)$ of 21 ( $\beta$ anomer) was obtained as a white solid. M.p. $72-74{ }^{\circ} \mathrm{C} .[\alpha]^{20}{ }_{\mathrm{D}}-28.5\left(\mathrm{c} 0.47, \mathrm{CH}_{2} \mathrm{Cl}_{2}\right) ;{ }^{1} \mathrm{H}-\mathrm{NMR}\left[\mathrm{CDCl}_{3}, 400 \mathrm{MHz}\right] \delta: 4.00(\mathrm{dd}, J=$ $\left.12.6 \mathrm{~Hz}, J=5.0 \mathrm{~Hz}, 1 \mathrm{H}, \mathrm{H}-5_{\mathrm{A}}\right), 4.14\left(\mathrm{dd}, J=12.6 \mathrm{~Hz}, J=3.1 \mathrm{~Hz}, 1 \mathrm{H}, \mathrm{H}-5_{\mathrm{B}}\right), 4.80-5.13(\mathrm{~m}, 24 \mathrm{H}$, $\mathrm{OCH}_{2} \mathrm{Ph}$ ), 5.43-5.48 (m, 1H, H-4), 5.57 (t, $J=5.0 \mathrm{~Hz}, 1 \mathrm{H}, \mathrm{H}-2$ ), 5.86 (wide s, 1H, H-3), 6.29 (d, $J=8.9 \mathrm{~Hz}, 1 \mathrm{H}), 6.33-6.40(\mathrm{~m}, 1 \mathrm{H}), 6.42(\mathrm{~d}, J=4.2 \mathrm{~Hz}, 1 \mathrm{H}, \mathrm{H}-1), 6.61-6.67$ (m, 2H, H-Ar), 7.10-7.57 (m, 63H, H-Ar), 7.64 (d, $J=8.7 \mathrm{~Hz}, 1 \mathrm{H}, \mathrm{H}-\mathrm{Ar}) .{ }^{13} \mathrm{C}-\mathrm{NMR}\left[\mathrm{CDCl}_{3}, 100 \mathrm{MHz}\right] \delta$ $63.34\left(\mathrm{CH}_{2}\right), 67.07(2 \mathrm{CH}), 67.73(\mathrm{CH}), 70.79\left(\mathrm{CH}_{2}\right), 70.93\left(\mathrm{CH}_{2}\right), 70.96\left(\mathrm{CH}_{2}\right), 71.02\left(\mathrm{CH}_{2}\right)$, 75.66 ( $\left(\mathrm{CH}_{2}\right), 75.69\left(\mathrm{CH}_{2}\right), 75.73\left(\mathrm{CH}_{2}\right), 75.77\left(\mathrm{CH}_{2}\right), 76.29\left(\mathrm{CH}_{2}\right), 76.41\left(\mathrm{CH}_{2}\right), 76.48\left(\mathrm{CH}_{2}\right)$, $76.54\left(\mathrm{CH}_{2}\right), 91.99(\mathrm{CH}), 108.39(\mathrm{CH}), 108.4(\mathrm{CH}), 108.65(\mathrm{CH}), 108.87(\mathrm{CH}), 117.26(\mathrm{C})$, 
$117.60(\mathrm{C}), 117.89(\mathrm{C}), 118.29(\mathrm{C}), 127.52(\mathrm{CH}), 127.58(\mathrm{CH}), 127.61(\mathrm{CH}), 127.67(\mathrm{CH})$, $127.75(\mathrm{CH}), 127.85(\mathrm{CH}), 128.08(\mathrm{CH}), 128.13(\mathrm{CH}), 128.16(\mathrm{CH}), 128.18(\mathrm{CH}), 128.21(\mathrm{CH})$, 128.23 (CH), $128.27(\mathrm{CH}), 128.30(\mathrm{CH}), 128.38(\mathrm{CH}), 128.40(\mathrm{CH}), 128.43(\mathrm{CH}), 128.46(\mathrm{CH})$, $128.49(\mathrm{CH}), 128.54(\mathrm{CH}), 128.68(\mathrm{CH}), 128.72(\mathrm{CH}), 128.74(\mathrm{CH}), 128.77(\mathrm{CH}), 128.80(\mathrm{CH})$, $128.82(\mathrm{CH}), 128.85(\mathrm{CH}), 128.89(\mathrm{CH}), 128.93(\mathrm{CH}), 128.95(\mathrm{CH}), \quad 128.99(\mathrm{CH}), 129.10$ (CH), $129.17(\mathrm{CH}), 135.98$ (C), 136.00 (C), 136.18 (C), 136.22 (C), 137.25 (C), 137.27 (C), 137.31 (C), 137.39 (C), 137.41 (C), 137.44 (C), 142.58 (C), 142.68 (C), 142.78 (C), 154.23 (C), 154.49 (C), 154.64 (C), 154.81 (C), 156.7 (C), 156.89 (C), 157.00 (C), 157.45 (C), 162.80 $(\mathrm{C}=\mathrm{O}), 163.18(\mathrm{C}=\mathrm{O}), 163.36(\mathrm{C}=\mathrm{O}), 164.02(\mathrm{C}=\mathrm{O}) . \mathrm{HRMS}(\mathrm{ES}+): \mathrm{m} / \mathrm{z}$ calculated: 1838.6601; found: $1857.7013\left(\mathrm{M}+\mathrm{NH}_{4}\right),{ }^{+} 1862.6538(\mathrm{M}+\mathrm{Na}){ }^{+}$Anal. Calcd. for $\mathrm{C}_{117} \mathrm{H}_{98} \mathrm{O}_{21}$ : C, 76.37; H, 5.37. Found: C, 76.19; H, 5.20.

\section{$\alpha$-D-Ribopiranose tetrakis(2,3,4-trihydroxybenzoate) (22)}

Following the general deprotection procedure the benzyl protected derivative 20 (100 mg, $0.054 \mathrm{mmol}$ ) gave $40 \mathrm{mg}$ of a residue that was purified by trituration with dichloromethane to give $15.9 \mathrm{mg}(40 \%)$ of the deprotected $\alpha$ anomer 22 as a white amorphous solid. ${ }^{1} \mathrm{H}-\mathrm{NMR}$ $\left[\mathrm{CD}_{3} \mathrm{OD}, 400 \mathrm{MHz}\right] \delta 4.13(\mathrm{dd}, J=4.2 \mathrm{~Hz}, J=11.5 \mathrm{~Hz}, 1 \mathrm{H}, \mathrm{H}-5), 4.45(\mathrm{dd}, J=9.1 \mathrm{~Hz}, J=11.5$ $\mathrm{Hz}, 1 \mathrm{H}, \mathrm{H}-5$ ), 5.60 (ddd, $J=4.2 \mathrm{~Hz}, J=4.0 \mathrm{~Hz}, J=8.2 \mathrm{~Hz}, 1 \mathrm{H}, \mathrm{H}-4$ ), 5.76 (t, $J=3.5 \mathrm{~Hz}, 1 \mathrm{H}, \mathrm{H}-$ 2), 6.15 (bs, 1H, H-3), 6.17-6.24 (m, 3H, H-Ar), 6.32 (d, $J=8.8 \mathrm{~Hz}, 1 \mathrm{H}, \mathrm{H}-\mathrm{Ar}), 6.56$ (d, $J=3.9$ $\mathrm{Hz}, 1 \mathrm{H}, \mathrm{H}-1)$, 7.01-7.11 (m, 2H, H-Ar), 7.35-7.43 (m, 2H, H-Ar). ${ }^{13} \mathrm{C}-\mathrm{NMR}$ [CD $\left.{ }_{3} \mathrm{OD}, 100 \mathrm{MHz}\right]$ $\delta 67.41(\mathrm{CH}), 68.22(\mathrm{CH}), 68.99(\mathrm{CH}), 90.71(\mathrm{CH}), 105.15(\mathrm{C}), 105.25(\mathrm{C}), 105.38(\mathrm{C}), 108.74$ $(\mathrm{CH}), 108.85(\mathrm{CH}), 108.87(\mathrm{CH}), 108.90(\mathrm{CH}), 122.49(\mathrm{CH}), 122.54(\mathrm{CH}), 122.83(\mathrm{CH}), 123.05$ (CH), 133.66 (C), 133.78 (C), 152.31 (C), 152.40 (C), 152.44 (C), 152.56 (C), 153.22 (C), 
$153.24(\mathrm{C}), 153.31(\mathrm{C}), 153.52(\mathrm{C}), 170.04(\mathrm{C}=\mathrm{O}), 170.05(\mathrm{C}=\mathrm{O}), 170.23(\mathrm{C}=\mathrm{O}), 170.74(\mathrm{C}=\mathrm{O})$. MS (ES+): $m / z \quad 781.2(\mathrm{M}+\mathrm{Na})^{+}, \quad 589.2(\mathrm{M}-169$, corresponding to the loss of 2,3,4trihydroxybenzoate) $)^{+}$.

\section{ß-D-Ribopiranose tetrakis(2,3,4-trihydroxybenzoate) (23)}

Following the general deprotection procedure the benzyl protected derivative 21 (100 $\mathrm{mg}$, $0.054 \mathrm{mmol})$ gave, after freeze-drying, 34,5 $\mathrm{mg}(84 \%)$ of the deprotected $\beta$ anomer 23 as an amorphous yellow solid. $[\alpha]^{20}{ }_{\mathrm{D}}-61.8$ (c 3.45, $\left.\mathrm{CH}_{3} \mathrm{OH}\right) ;{ }^{1} \mathrm{H}-\mathrm{NMR}\left[\mathrm{CD}_{3} \mathrm{OD}, 400 \mathrm{MHz}\right] \delta 4.21$ (dd, $1 \mathrm{H}, J=3.5 \mathrm{~Hz}, J=13.3 \mathrm{~Hz}, \mathrm{H}-5 \mathrm{~A}), 4.46(\mathrm{dd}, 1 \mathrm{H}, J=2.3 \mathrm{~Hz}, J=13.3 \mathrm{~Hz}, \mathrm{H}-5 \mathrm{~B}), 5.62-5.70$ (m, 2H, H-2, H-4), 6.01 (t, 1H, J=3.9 Hz, H-3), 6.20-6.30 (m, 3H, H-Ar), 6.49 (d, 1H, J= 8.9 Hz, H-Ar), 6.57 (d, 1H, $J=2.7 \mathrm{~Hz}, \mathrm{H}-1), 6.93$ (d, 1H, $J=8.9 \mathrm{~Hz}, \mathrm{H}-\mathrm{Ar})$, 7.30-7.40 (m, 2H, H-Ar), $7.47(\mathrm{~d}, 1 \mathrm{H}, J=8.9 \mathrm{~Hz}, \mathrm{H}-\mathrm{Ar}) .{ }^{13} \mathrm{C}-\mathrm{NMR}\left[\mathrm{CD}_{3} \mathrm{OD}, 100 \mathrm{MHz}\right] \delta 64.76\left(\mathrm{CH}_{2}\right), 67.73(\mathrm{CH}), 68.88$ $(\mathrm{CH}), 69.07(\mathrm{CH}), 93.84(\mathrm{CH}), 105.56(\mathrm{C}), 105.67(\mathrm{C}), 106.03(\mathrm{C}), 109.16(\mathrm{CH}), 109.28(\mathrm{CH})$, $109.35(\mathrm{CH}), 109.64(\mathrm{CH}), 122.80(\mathrm{CH}), 123.32(\mathrm{CH}), 123.61(\mathrm{CH}), 123.67(\mathrm{CH}), 134.10(\mathrm{C})$, 134.12 (C), 134.15 (C), 134.35 (C), 152.81 (C), 152.86 (C), 153.22 (C), 153.56 (C), 153.78 (C), $154.20(\mathrm{C}), 169.75(\mathrm{C}=\mathrm{O}), 170.52(\mathrm{C}=\mathrm{O}), 170.96(\mathrm{C}=\mathrm{O}), 171.38(\mathrm{C}=\mathrm{O}) . \mathrm{MS}(\mathrm{ES}+): m / z 776.4$ $\left(\mathrm{M}+\mathrm{H}_{2} \mathrm{O}\right)^{+}, 589.3(\mathrm{M}-169 \text {, corresponding to the loss of 2,3,4-trihydroxybenzoate })^{+}$. Anal. Calcd. for $\mathrm{C}_{33} \mathrm{H}_{26} \mathrm{O}_{21}$ : C, 52.25; H, 3.45. Found: C, 52.27; H, 3.99.

\section{$\beta$-D-Maltose octakis [3,4,5-tris(phenylmethoxy)benzoate] (24)}

Following the general carbohydrate esterification procedure, a solution of D-maltose monohydrate $(50 \mathrm{mg}, 0.14 \mathrm{mmol})$ in dry dichloromethane $(70 \mathrm{~mL})$ was treated with $2^{18-20}(690$ mg, 1.57 mmoles, $11.2 \mathrm{eq})$, DCC (369 mg, $1.8 \mathrm{mmol}, 12.8 \mathrm{eq})$ and DMAP (219 mg, $1.8 \mathrm{mmol}$, 
12.8 eq) to give a residue that was purified by column chromatography on silica gel using a mixture of dichloromethane/toluene/ethyl acetate $75: 25: 1$ to give $440 \mathrm{mg}(86 \%)$ of $\mathbf{2 4}$ as a white solid. Mp 59-61 ${ }^{\circ} \mathrm{C} .[\alpha]^{24}{ }_{\mathrm{D}}-12,3^{\circ}\left(\mathrm{c} 0.153, \mathrm{CH}_{2} \mathrm{Cl}_{2}\right)$. HPLC: $t_{R(S)}=3.78 .{ }^{1} \mathrm{H}$ NMR $\left(\mathrm{CDCl}_{3}, 300\right.$ MHz) $\delta:$ 4.20-4.57 (m, 7H, H-4, H-5, H-6 and H-6'), 4.62-5.08 (m, 48H, $\left.\mathrm{CH}_{2}-\mathrm{Ph}\right), 5.36$ (dd, $J=$ $\left.3.7 \mathrm{~Hz}, J=10.7 \mathrm{~Hz}, 1 \mathrm{H}, \mathrm{H}-2^{\prime}\right), 5.50-5.60$ (m, 2H, H-1' and H-2), 5.69 (t, $J=9.9 \mathrm{~Hz}, 1 \mathrm{H}, \mathrm{H}-4^{\prime}$ ), $6.00(\mathrm{t}, J=9.7 \mathrm{~Hz}, 1 \mathrm{H}, \mathrm{H}-3), 6.09-6.17$ (m, 2H, H-1 and H-3'), 6.82-7.38 (m, 136H, CH-Ar). $\mathrm{EM}(\mathrm{ES}+) m / z: 3744(\mathrm{M}+\mathrm{Na})^{+}$.

\section{B-D-Maltose octakis(3,4,5-trihydroxybenzoate) (25)}

Following the general deprotection procedure, the benzyl protected derivative $\mathbf{2 4}(125 \mathrm{mg}$, $0.034 \mathrm{mmol}$ ) gave $44.3 \mathrm{mg}$ ( $82 \%$ yield) of the deprotected $\beta$ anomer 25 as a white solid. Mp $>190{ }^{\circ} \mathrm{C}(\mathrm{dec}) \cdot[\alpha]^{24}{ }_{\mathrm{D}}+38.3^{\circ}$ (c 0.15 , acetone). HPLC: $t_{R(S)}=2.84 \mathrm{~min} .{ }^{1} \mathrm{H}$ NMR $\left(\mathrm{CD}_{3} \mathrm{OD}, 400\right.$ MHz) $\delta$ : 4.12 (bs, 2H, H-6'), 4.26 (dt, $J=2.0 \mathrm{~Hz}, J=10.0 \mathrm{~Hz}, 1 \mathrm{H}, \mathrm{H}-5$ '), 4.38 (dt, $J=2.7 \mathrm{~Hz}, J$ $=9.7 \mathrm{~Hz}, 1 \mathrm{H}, \mathrm{H}-5), 4.59$ (t, $J=9.3 \mathrm{~Hz}, 1 \mathrm{H}, \mathrm{H}-4), 4.74$ (bs, 2H, H-6), 5.13 (dd, $J=3.9 \mathrm{~Hz}, J=$ $10.5 \mathrm{~Hz}, 1 \mathrm{H}, \mathrm{H}-2$ '), 5.43 (dd, $J=8.4 \mathrm{~Hz}, \mathrm{~J}=9.8 \mathrm{~Hz}, 1 \mathrm{H}, \mathrm{H}-2), 5.55$ (t, $J=9.8 \mathrm{~Hz}, 1 \mathrm{H}, \mathrm{H}-4^{\prime}$ ), $5.78\left(\mathrm{~d}, J=3.9 \mathrm{~Hz}, 1 \mathrm{H}, \mathrm{H}-1^{\prime}\right), 5.82-5.91$ (m, 2H, H-3 and H-3'), 6.17 (d, $\left.J=8.3,1 \mathrm{H}, \mathrm{H}-1\right), 6.80$ (s, 2H, H-Ar), 6.84 (s, 2H, H-Ar), 6.87 (s, 2H, H-Ar), 6.89 (s, 2H, H-Ar), 6.95 (s, 2H, H-Ar), 7.02 (s, 2H, H-Ar), 7.07 (s, 2H, H-Ar), 7.20 (s, 2H, H-Ar). ${ }^{13} \mathrm{C}$ NMR $\left(\mathrm{CD}_{3} \mathrm{OD}, 100 \mathrm{MHz}\right) \delta$ : $62.56\left(\mathrm{CH}_{2}\right), 64.00(\mathrm{CH}), 69.49(\mathrm{CH}), 70.64(\mathrm{CH}), 71.14(\mathrm{CH}), 71.78(\mathrm{CH}), 72.71(\mathrm{CH}), 72.77$ $(\mathrm{CH}), 74.75(\mathrm{CH}), 76.30(\mathrm{CH}), 93.60(\mathrm{CH}), 97.63(\mathrm{CH}), 110.29(\mathrm{CH}), 110.44(\mathrm{CH}), 110.49$ $(\mathrm{CH}), 110.58(\mathrm{CH}), 110.62(\mathrm{CH}), 110.98(\mathrm{CH}), 119.77(\mathrm{C}), 120.18(\mathrm{C}), 120.34(\mathrm{C}), 120.43(\mathrm{C})$, 120.50 (C), 120.66 (C), 121.03 (C), 139.96 (C), 140.03 (C), 140.15 (C), 140.17 (C), 140.21 (C), 140.34 (C), 140.43 (C), 140.74 (C), 146.03 (C), 146.19 (C), 146.22 (C), 146.24 (C), 146.39 (C), 
$146.46(\mathrm{C}), 146.53(\mathrm{C}), 146.74(\mathrm{C}), 166.25(\mathrm{C}=\mathrm{O}), 166.34(\mathrm{C}=\mathrm{O}), 166.71(\mathrm{C}=\mathrm{O}), 167.10(\mathrm{C}=\mathrm{O})$, $167.12(\mathrm{C}=\mathrm{O}), 167.56(\mathrm{C}=\mathrm{O}), 167.73(\mathrm{C}=\mathrm{O}), 168.23(\mathrm{C}=\mathrm{O}) . \mathrm{EM}(\mathrm{ES}+) \mathrm{m} / \mathrm{z}: 1559(\mathrm{M}+\mathrm{H})^{+}$. Anal. Calcd. for $\mathrm{C}_{68} \mathrm{H}_{54} \mathrm{O}_{43}$ : C, 52.38; H,3.49. Found: C, 52.25; H, 3.53.

\section{$\alpha, \alpha-D-T r e h a l o s e ~ o c t a k i s[3,4,5-t r i s(p h e n y l m e t h o x y) b e n z o a t e](26)$}

Following the general carbohydrate esterification procedure, a solution of D-trehalose dihydrate $(50 \mathrm{mg}, 0.14 \mathrm{mmol})$ in dry dichloromethane $(70 \mathrm{~mL})$ was treated with $2^{18-20}(690 \mathrm{mg}$, 1.57 mmoles, $11.2 \mathrm{eq})$, DCC (369 mg, $1.8 \mathrm{mmol}, 12.8 \mathrm{eq})$ and DMAP (219 mg, $1.8 \mathrm{mmol}, 12.8$ eq) to give a residue that was purified by column chromatography on silica gel using a mixture of dichloromethane/toluene/ethyl acetate $75: 25: 1$ to give $398 \mathrm{mg}(81 \%)$ of $\mathbf{2 6}$ as a white solid. Mp 83-85 ${ }^{\circ} \mathrm{C} .[\alpha]^{24}+79.6^{\circ}\left(\mathrm{c} 0.156, \mathrm{CH}_{2} \mathrm{Cl}_{2}\right)$. HPLC: $t_{R(S)}=3.75 \mathrm{~min} .{ }^{1} \mathrm{H} \mathrm{NMR}\left(\mathrm{CDCl}_{3}, 400\right.$ MHz]) $\delta: 3.68(\mathrm{dd}, J=12.4 \mathrm{~Hz}, J=3.9 \mathrm{~Hz}, 2 \mathrm{H}, \mathrm{H}-6), 4.29(\mathrm{dd}, J=12.3 \mathrm{~Hz}, J=3.7 \mathrm{~Hz}, 2 \mathrm{H}, \mathrm{H}-$ 6), $4.44(\mathrm{dt}, J=10.1 \mathrm{~Hz}, J=3.9 \mathrm{~Hz}, 2 \mathrm{H}, \mathrm{H}-5), 4.56\left(\mathrm{~s}, 8 \mathrm{H}, \mathrm{CH}_{2}-\mathrm{Ph}\right), 4.66-4.98\left(\mathrm{~m}, 40 \mathrm{H}, \mathrm{CH}_{2}-\right.$ Ph), $5.21(\mathrm{dd}, J=10.3 \mathrm{~Hz}, 4.1 \mathrm{~Hz}, 2 \mathrm{H}, \mathrm{H}-2), 5.62$ (t, $J=9.9 \mathrm{~Hz}, 2 \mathrm{H}, \mathrm{H}-4), 5.87$ (d, $J=4.2 \mathrm{~Hz}$, 2H, H-1), 6.38 (t, $J=10.0 \mathrm{~Hz}, 2 \mathrm{H}, \mathrm{H}-3), 6.89-7.29$ (m, 130H, H-Ar), 7.42 (s, 6H, H-Ar). ${ }^{13} \mathrm{C}-$ $\mathrm{NMR}\left[\mathrm{CDCl}_{3}, 100 \mathrm{MHz}\right] \delta 62.31\left(2 \mathrm{CH}_{2}\right), 68.60(2 \mathrm{CH}), 70.00(2 \mathrm{CH}), 70.87\left(\mathrm{CH}_{2}\right), 70.99\left(\mathrm{CH}_{2}\right)$, $71.09\left(\mathrm{CH}_{2}\right), 71.17\left(2 \mathrm{CH}, \mathrm{CH}_{2}\right), 72.51(2 \mathrm{CH}), 74.93\left(\mathrm{CH}_{2}\right), 75.01\left(\mathrm{CH}_{2}\right), 75.05\left(\mathrm{CH}_{2}\right), 95.59$ (2CH), $108.98(\mathrm{CH}), 109.01(\mathrm{CH}), 123.34(\mathrm{C}), 123.78(\mathrm{C}), 123.87(\mathrm{C}), 124.47(\mathrm{C}), 127.53(\mathrm{CH})$, $127.58(\mathrm{CH}), 127.61(\mathrm{CH}), 127.65(\mathrm{CH}), 127.67(\mathrm{CH}), 127.73(\mathrm{CH}), 127.76(\mathrm{CH}), 127.82(\mathrm{CH})$, $127.88(\mathrm{CH}), 127.93(\mathrm{CH}), 128.00(\mathrm{CH}), 128.02(\mathrm{CH}), 128.09(\mathrm{CH}), 128.11(\mathrm{CH}), 128.22(\mathrm{CH})$, $128.24(\mathrm{CH}), 128.32(\mathrm{CH}), 128.34(\mathrm{CH}), 128.36(\mathrm{CH}), 128.45(\mathrm{CH}), 136.13(\mathrm{C}), 136.30(\mathrm{C})$, 136.67 (C), 137.25 (C), 137.45 (C), 137.58 (C), 142.53 (C), 143.17 (C), 143.19 (C), 143.26 (C), 
152.45 (C), $152.61(\mathrm{C}), 152.64(\mathrm{C}), 152.83(\mathrm{C}), 165.23(\mathrm{C}=\mathrm{O}), 165.31(\mathrm{C}=\mathrm{O}), 165.42(\mathrm{C}=\mathrm{O})$, $165.98(\mathrm{C}=\mathrm{O}) . \mathrm{EM}(\mathrm{ES}+) m / z: 3744\left(\mathrm{M}+\mathrm{Na}^{)^{+}}\right.$.

\section{$\alpha, \alpha-D-T r e h a l o s e ~ o c t a k i s(3,4,5$-trihydroxybenzoate) (27)}

Following the general deprotection procedure the benzyl protected derivative $\mathbf{2 6}(200 \mathrm{mg}$, $0.053 \mathrm{mmol})$ gave $66 \mathrm{mg}$ (80\% yield) of 27 as a white solid. $\mathrm{Mp}>200{ }^{\circ} \mathrm{C}(\mathrm{dec}) .[\alpha]^{24}+19.7^{\circ}(\mathrm{c}$ 0.155, acetone). HPLC: $t_{R}(x)=9.18 \mathrm{~min} .{ }^{1} \mathrm{H}$ NMR $\left(\mathrm{CD}_{3} \mathrm{OD}, 400 \mathrm{MHz}\right) \delta: 3.63(\mathrm{~m}, 2 \mathrm{H}, \mathrm{H}-6$ and H-6'), 3.93 (d, $J=12.4$ Hz, 2H, H-6 and H-6'), 4.22 (d, $J=10.3 \mathrm{~Hz}, 2 \mathrm{H}, \mathrm{H}-5$ and H-5'), 5.26 (dd, $J=4.0 \mathrm{~Hz}, J=10.3 \mathrm{~Hz}, 2 \mathrm{H}, \mathrm{H}-2$ and H-2'), 5.60 (t, $J=10.1 \mathrm{~Hz}, 2 \mathrm{H}, \mathrm{H}-4$ and H-4'), 5.70 (d, $J=3.7 \mathrm{~Hz}, 2 \mathrm{H}, \mathrm{H}-1$ and H-1'), 6.02 (t, $J=10.1 \mathrm{~Hz}, 2 \mathrm{H}, \mathrm{H}-3$ and H-3'), 6.90 (s, 4H, H-Ar), 6.98 (s, 4H, H-Ar), 7.05 (s, 4H, H-Ar), 7.20 (s, 4H, H-Ar). ${ }^{13} \mathrm{C}$ NMR $\left(\mathrm{CD}_{3} \mathrm{OD}, 100 \mathrm{MHz}\right) \delta: 61.89$ $\left(2 \mathrm{CH}_{2}\right), 69.07(2 \mathrm{CH}), 70.01(2 \mathrm{CH}), 71.58(2 \mathrm{CH}), 72.56(2 \mathrm{CH}), 94.89(2 \mathrm{CH}), 110.30(\mathrm{CH})$, $110.43(\mathrm{CH}), 110.49(\mathrm{CH}), 110.62(\mathrm{CH}), 119.96(\mathrm{C}), 120.11(\mathrm{C}), 120.46(\mathrm{C}), 120.99(\mathrm{C}), 139.97$ (C), 140.25 (C), 140.33 (C), 140.79 (C), 146.30 (C), 146.38 (C), 146.44 (C), 146.69 (C), 166.78 $(\mathrm{C}=\mathrm{O}), 166.80(\mathrm{C}=\mathrm{O}), 167.72(\mathrm{C}=\mathrm{O}), 167.74(\mathrm{C}=\mathrm{O}) . \mathrm{EM}(\mathrm{ES}+) \mathrm{m} / z: 1559(\mathrm{M}+\mathrm{H})^{+}$. Anal. Calcd. for $\mathrm{C}_{68} \mathrm{H}_{54} \mathrm{O}_{43}$ : C, 52.38; H, 3.49. Found: C, 52.61; H, 3.64.

\section{ß-D-Maltose octakis[2,3,4-tris(phenylmethoxy)benzoate] (28)}

Following the general carbohydrate esterification procedure, a solution of D-maltose monohydrate $(73 \mathrm{mg}, 0.20 \mathrm{mmol})$ in dry dichloromethane $(100 \mathrm{~mL})$ was treated with $\mathbf{1 1}^{21}(1 \mathrm{~g}$, 2.3 mmoles, $11.2 \mathrm{eq})$, DCC (523.5 mg, $2.56 \mathrm{mmol}, 12.8 \mathrm{eq})$ and DMAP (311.3 mg, $2.56 \mathrm{mmol}$, 12.8 eq) to give a residue that was purified by column chromatography on silica gel using a 
mixture of hexane/ethyl acetate 4:1 and then toluene:ethyl acetate: (20:1) to give $397.2 \mathrm{mg}$ (53 \%) of 28 as a white solid. Mp. $114-115^{\circ} \mathrm{C} .[\alpha]^{20}{ }_{\mathrm{D}}+15.8\left(\mathrm{c} 0.50, \mathrm{CH}_{2} \mathrm{Cl}_{2}\right) ;{ }^{1} \mathrm{H}-\mathrm{NMR}\left[\mathrm{CDCl}_{3}, 300\right.$ MHz] $\delta 3.96-4.08(\mathrm{~m}, 2 \mathrm{H}), 4.50-5.22(\mathrm{~m}, 54 \mathrm{H}), 5.55(\mathrm{t}, J=8.7 \mathrm{~Hz}, 1 \mathrm{H}), 5.63(\mathrm{dd}, J=3.4 \mathrm{~Hz}, J=$ $10.4 \mathrm{~Hz}, 1 \mathrm{H}), 5.76-5.86(\mathrm{~m}, 2 \mathrm{H}), 5.96(\mathrm{t}, J=8.7 \mathrm{H}, 1 \mathrm{H}), 6.18-6.30(\mathrm{~m}, 4 \mathrm{H}), 6.32(\mathrm{~d}, J=9.0 \mathrm{~Hz}$, 1H, H-Ar), 6.40-6.50 (m, 2H, H-Ar), 6.54 (d, $J=9.0 \mathrm{~Hz}, 1 \mathrm{H}, \mathrm{H}-\mathrm{Ar}), 6.74$ (d, $J=9.0 \mathrm{~Hz}, 1 \mathrm{H}, \mathrm{H}-$ Ar), 6.84 (d, $J=9.0 \mathrm{~Hz}, 1 \mathrm{H}, \mathrm{H}-\mathrm{Ar}), 7.10-7.78$ (m, 124H, H-Ar), 7.79 (d, $J=9.0 \mathrm{~Hz}, 1 \mathrm{H}, \mathrm{H}-\mathrm{Ar}$ ), $7.86(\mathrm{~d}, J=9.0 \mathrm{~Hz}, 1 \mathrm{H}, \mathrm{H}-\mathrm{Ar}), 7.96(\mathrm{~d}, J=9.0 \mathrm{~Hz}, 1 \mathrm{H}, \mathrm{H}-\mathrm{Ar}) .{ }^{13} \mathrm{C}-\mathrm{NMR}\left[\mathrm{CDCl}_{3}, 100 \mathrm{MHz}\right] \delta$ $62.67\left(\mathrm{CH}_{2}\right), 63.68\left(\mathrm{CH}_{2}\right), 68.63(\mathrm{CH}), 69.33(\mathrm{CH}), 69.83(\mathrm{CH}), 69.85(\mathrm{CH}), 70.32\left(\mathrm{CH}_{2}\right), 70.46$ $\left(\mathrm{CH}_{2}\right), 70.49\left(\mathrm{CH}_{2}\right), 70.51\left(\mathrm{CH}_{2}\right), 70.55\left(\mathrm{CH}_{2}\right), 70.67\left(\mathrm{CH}_{2}\right), 70.74\left(\mathrm{CH}_{2}\right), 70.78(\mathrm{CH}), 73.75$ $(\mathrm{CH}), 74.16(\mathrm{CH}), 74.25(\mathrm{CH}), 75.31\left(\mathrm{CH}_{2}\right), 75.37\left(\mathrm{CH}_{2}\right), 75.40\left(\mathrm{CH}_{2}\right), 75.50\left(\mathrm{CH}_{2}\right), 75.60$ $\left(\mathrm{CH}_{2}\right), 75.68\left(\mathrm{CH}_{2}\right), 75.86\left(\mathrm{CH}_{2}\right), 75.95\left(\mathrm{CH}_{2}\right), 75.96\left(\mathrm{CH}_{2}\right), 76.07\left(\mathrm{CH}_{2}\right), 76.11\left(\mathrm{CH}_{2}\right), 76.28$ $\left(\mathrm{CH}_{2}\right), 76.34\left(\mathrm{CH}_{2}\right), 91.91(\mathrm{CH}), 97.26(\mathrm{CH}), 108.44(\mathrm{CH}), 108.49(\mathrm{CH}), 108.57(\mathrm{CH}), 108.66$ $(\mathrm{CH}), 108.85(\mathrm{CH}), 116.16(\mathrm{C}), 116.19$ (C), 116.33 (C), 116.54 (C), 116.64 (C), 116.74 (C), $117.85(\mathrm{C}), 118.22(\mathrm{C}), 127.36(\mathrm{CH}), 127.42(\mathrm{CH}), 127.43(\mathrm{CH}), 127.47(\mathrm{CH}), 127.51(\mathrm{CH})$, $127.57(\mathrm{CH}), 127.64(\mathrm{CH}), 127.68(\mathrm{CH}), 127.75(\mathrm{CH}), 127.77(\mathrm{CH}), 127.81(\mathrm{CH}), 127.85(\mathrm{CH})$, $127.90(\mathrm{CH}), 127.94(\mathrm{CH}), 127.96(\mathrm{CH}), 127.99(\mathrm{CH}), 128.02(\mathrm{CH}), 128.07(\mathrm{CH}), 128.11(\mathrm{CH})$, $128.13(\mathrm{CH}), 128.19(\mathrm{CH}), 128.21(\mathrm{CH}), 128.22(\mathrm{CH}), 128.27(\mathrm{CH}), 128.29(\mathrm{CH}), 128.32(\mathrm{CH})$, $128.36(\mathrm{CH}), 128.38(\mathrm{CH}), 128.41(\mathrm{CH}), 128.46(\mathrm{CH}), 128.49(\mathrm{CH}), 128.52(\mathrm{CH}), 128.55(\mathrm{CH})$, $128.58(\mathrm{CH}), 128.69(\mathrm{CH}), 128.76(\mathrm{CH}), 128.81(\mathrm{CH}), 128.87(\mathrm{CH}), 128.94(\mathrm{CH}), 128.96(\mathrm{CH})$, $129.00(\mathrm{CH}), 129.05(\mathrm{CH}), 129.12(\mathrm{CH}), 129.24(\mathrm{CH}), 136.00(\mathrm{C}), 136.06(\mathrm{C}), 136.08(\mathrm{C})$, 136.10 (C), 136.14 (C), 136.28 (C), 137.20 (C), 137.26 (C), 137.28 (C), 137.35 (C), 137.41 (C), 137.45 (C), 137.47 (C), 137.51 (C), 137.81 (C), 137.87 (C), 142.26 (C), 142.27 (C), 142.34 (C), 142.45 (C), 142.59 (C), 142.62 (C), 154.26 (C), 154.30 (C), 154.33 (C), 154.49 (C), 154.55 (C), 
154.78 (C), 156.69 (C), 156.71 (C), 156.74 (C), 156.93 (C), 156.97 (C), 157.13 (C), 157.16 (C), $161.89(\mathrm{C}=\mathrm{O}), 162.71(\mathrm{C}=\mathrm{O}), 162.89(\mathrm{C}=\mathrm{O}), 162.98(\mathrm{C}=\mathrm{O}), 163.05(\mathrm{C}=\mathrm{O}), 163.10(\mathrm{C}=\mathrm{O})$, 164.06 $(\mathrm{C}=\mathrm{O}), 164.40(\mathrm{C}=\mathrm{O})$. Anal. Calcd. for $\mathrm{C}_{236} \mathrm{H}_{198} \mathrm{O}_{43}$ : C, 76.16; H, 5.36. Found: $\mathrm{C}, 76.40$; H, 5.32. HRMS (ES+): $\mathrm{m} / \mathrm{z}$ calculated: 3719.3307 ; found: $3744.3359(\mathrm{M}+\mathrm{Na})^{+}$.

\section{$\beta$-D-Maltose octakis(2,3,4-trihydroxybenzoate) (29)}

Following the general deprotection procedure the benzyl protected derivative $\mathbf{2 8}$ (100 mg, $0.026 \mathrm{mmol})$ gave $26.8 \mathrm{mg}\left(66 \%\right.$ yield) of 29 as a yellow solid. Mp $213-215^{\circ} \mathrm{C} .[\alpha]^{20}{ }_{\mathrm{D}}+0.72(\mathrm{c}$ $1.25, \mathrm{CH}_{3} \mathrm{OH}$ ); ${ }^{1} \mathrm{H}-\mathrm{NMR}$ [CD $\left.{ }_{3} \mathrm{OD}, 400 \mathrm{MHz}\right] \delta 4.42-4.44$ (m, 2H, H-6'), 4.52-4.53 (m, 2H, CH5, H-5'), 4.65-4.68 (m, 1H, H-4), 4.74-4.78 (m, 2H, H-6), 5.28 (dd, $J=3.5 \mathrm{~Hz}, J=10.3 \mathrm{~Hz}, 1 \mathrm{H}$, H-2'), 5.56 (dd, $J=7.5 \mathrm{~Hz}, J=8.6 \mathrm{~Hz}, 1 \mathrm{H}, \mathrm{H}-2), 5.61$ (t, $J=9.7 \mathrm{~Hz}, 1 \mathrm{H}, \mathrm{H}-4$ ') 5.83 (d, $J=3.9$ Hz, 1H, H-1'), 5.93 (t, $J=8.4$ Hz, 1H, H-3), 6.03 (t, $J=9.7$ Hz, 1H, H-3'), 6.20-6.25 (m, 2H, HAr), 6.28-6.37 (m, 7H, H-1, H-Ar), 7.07 (d, $J=8.9$ Hz, 2H, H-Ar), 7.14 (d, $J=8.9$ Hz, 1H, HAr), 7.19-7.23 (m, 3H, H-Ar), 7.26 (d, $J=8.9 \mathrm{~Hz}, 1 \mathrm{H}, \mathrm{H}-\mathrm{Ar}), 7.41$ (d, $J=8.9 \mathrm{~Hz}, 1 \mathrm{H}, \mathrm{H}-\mathrm{Ar}$ ). ${ }^{13} \mathrm{C}-\mathrm{NMR}\left[\mathrm{CD}_{3} \mathrm{OD}, 100 \mathrm{MHz}\right] \delta 64.36\left(\mathrm{CH}_{2}\right), 65.07\left(\mathrm{CH}_{2}\right), 70.52(\mathrm{CH}), 71.04(\mathrm{CH}), 71.52(\mathrm{CH})$, $72.72(\mathrm{CH}), 72.91(\mathrm{CH}), 75.02(\mathrm{CH}), 75.04(\mathrm{CH}), 76.36(\mathrm{CH}), 93.63(\mathrm{CH}), 98.33(\mathrm{CH}), 105.28$ (C), $105.34(\mathrm{C}), 105.56(\mathrm{C}), 105.99(\mathrm{C}), 109.19(\mathrm{CH}), 109.44(\mathrm{CH}), 109.52(\mathrm{CH}), 123.00(\mathrm{CH})$, $123.12(\mathrm{CH}), 123.32(\mathrm{CH}), 123.48(\mathrm{CH}), 126.61(\mathrm{CH}), 133.88(\mathrm{C}), 133.96(\mathrm{C}), 134.02(\mathrm{C})$, 134.23 (C), 152.71 (C), 152.79 (C), 152.84 (C), 152.91 (C), 153.10 (C), 153.43 (C), 153.64 (C), $153.81(\mathrm{C}), 153.86(\mathrm{C}), 153.96(\mathrm{C}), 154.32(\mathrm{C}), 169.95(\mathrm{C}=\mathrm{O}), 170.45(\mathrm{C}=\mathrm{O}), 170.53(\mathrm{C}=\mathrm{O})$, $170.56(\mathrm{C}=\mathrm{O}), 170.89(\mathrm{C}=\mathrm{O}), 170.99(\mathrm{C}=\mathrm{O}), 171.35(\mathrm{C}=\mathrm{O}), 171.74(\mathrm{C}=\mathrm{O}) . \operatorname{HRMS}(\mathrm{ES}+): \mathrm{m} / \mathrm{z}$ calculated:1558.2039; found:1576.2377 $\left(\mathrm{M}+\mathrm{NH}_{4}\right)^{+}$. 


\section{$\alpha, \alpha-D-T r e h a l o s e ~ o c t a k i s[2,3,4-t r i s(p h e n y l m e t h o x y) b e n z o a t e](30)$}

Following the general carbohydrate esterification procedure, a solution of D-trehalose dihydrate $(114.9 \mathrm{mg}, 0.30 \mathrm{mmol})$ in dry dichloromethane $(150 \mathrm{~mL})$ was treated with $\mathbf{1 1}^{21}(1.5 \mathrm{~g}$, $3.4 \mathrm{mmol}, 11.2 \mathrm{eq}$ ), DCC (777 mg, $3.8 \mathrm{mmol}, 12.8 \mathrm{eq}$ ) and DMAP (462 mg, $3.8 \mathrm{mmol}, 12.8 \mathrm{eq}$ ) to give a residue that was purified by column chromatography on silica gel using a mixture of toluene/ethyl acetate $40: 1$ to give $888.3 \mathrm{mg}(79 \%)$ of $\mathbf{3 0}$ as a white solid. Mp 131-133 ${ }^{\circ} \mathrm{C}$. $[\alpha]^{20} \mathrm{D}$ $+93.4\left(\mathrm{c} 1.22, \mathrm{CH}_{2} \mathrm{Cl}_{2}\right) ;{ }^{1} \mathrm{H}-\mathrm{NMR}\left[\mathrm{CDCl}_{3}, 300 \mathrm{MHz}\right] \delta 4.38-4.56(\mathrm{~m}, 4 \mathrm{H}), 4.58-4.79(\mathrm{~m}, 10 \mathrm{H}$, CH2-Ph), 4.80-5.23 (m, 38H, $\left.\mathrm{CH}_{2} \mathrm{Ph}\right), 5.57$ (dd, $\left.J=3.7 \mathrm{~Hz}, J=10.4 \mathrm{~Hz}, 2 \mathrm{H}\right), 5.77$ (t, $J=10.4$ $\mathrm{Hz}, 2 \mathrm{H}), 5.84(\mathrm{~d}, J=3.7 \mathrm{~Hz}, 2 \mathrm{H}), 6.52-6.61(\mathrm{~m}, 4 \mathrm{H}), 6.68(\mathrm{~d}, J=9.0 \mathrm{~Hz}, 2 \mathrm{H}, \mathrm{H}-\mathrm{Ar}), 6.83(\mathrm{t}, J=$ $9.0 \mathrm{~Hz}, 4 \mathrm{H}, \mathrm{H}-\mathrm{Ar}$ ), 7.17-7.77 (m, 124H, H-Ar), 7.82 (t, $J=9.0 \mathrm{~Hz}, 4 \mathrm{H}, \mathrm{H}-\mathrm{Ar}$ ), 8.40 (d, $J=9.0$ $\mathrm{Hz}, 2 \mathrm{H}, \mathrm{H}-\mathrm{Ar}) .{ }^{13} \mathrm{C}-\mathrm{NMR}\left[\mathrm{CDCl}_{3}, 100 \mathrm{MHz}\right] \delta 62.16\left(2 \mathrm{CH}_{2}\right), 68.18(2 \mathrm{CH}), 68.98(2 \mathrm{CH}), 70.28$ (2CH), $70.43\left(\mathrm{CH}_{2}\right), 70.59\left(\mathrm{CH}_{2}\right), 70.63(2 \mathrm{CH}), 70.69\left(\mathrm{CH}_{2}\right), 75.32\left(\mathrm{CH}_{2}\right), 75.36\left(\mathrm{CH}_{2}\right), 75.54$ $\left(\mathrm{CH}_{2}\right), 75.60\left(\mathrm{CH}_{2}\right), 76.02\left(\mathrm{CH}_{2}\right), 76.15\left(\mathrm{CH}_{2}\right), 91.58(2 \mathrm{CH}), 108.45(\mathrm{CH}), 108.60(\mathrm{CH}), 108.68$ $(\mathrm{CH}), 109.27(\mathrm{CH}), 116.36(\mathrm{C}), 116.53(\mathrm{C}), 117.06(\mathrm{C}), 118.01(\mathrm{C}), 127.30(\mathrm{CH}), 127.40(\mathrm{CH})$, $127.54(\mathrm{CH}), 127.61(\mathrm{CH}), 127.67(\mathrm{CH}), 127.75(\mathrm{CH}), 127.81(\mathrm{CH}), 127.83(\mathrm{CH}), 127.86(\mathrm{CH})$, $127.90(\mathrm{CH}), 127.93(\mathrm{CH}), 128.00(\mathrm{CH}), 128.04(\mathrm{CH}), 128.10(\mathrm{CH}), 128.12(\mathrm{CH}), 128.14(\mathrm{CH})$, $128.16(\mathrm{CH}), 128.20(\mathrm{CH}), 128.29(\mathrm{CH}), 128.33(\mathrm{CH}), 128.36(\mathrm{CH}), 128.48(\mathrm{CH}), 128.50(\mathrm{CH})$, $128.52(\mathrm{CH}), 128.54(\mathrm{CH}), 128.64(\mathrm{CH}), 128.63(\mathrm{CH}), 128.73(\mathrm{CH}), 128.76(\mathrm{CH}), 128.92(\mathrm{CH})$, $129.05(\mathrm{CH}), 135.66(\mathrm{C}), 135.78(\mathrm{C}), 136.08(\mathrm{C}), 136.28(\mathrm{C}), 137.19$ (C), $137.20(\mathrm{C}), 137.23$ (C), 137.25 (C), 137.33 (C), 137.39 (C), 137.61 (C), 142.37 (C), 142.53 (C), 142.60 (C), 142.82

(C), 154.15 (C), 154.57 (C), 154.81 (C), 154.86 (C), 156.64 (C), 156.79 (C), 157.11 (C), 157.39 (C), $162.25(\mathrm{C}=\mathrm{O}), 162.90(\mathrm{C}=\mathrm{O}), 163.47(\mathrm{C}=\mathrm{O}), 164.01(\mathrm{C}=\mathrm{O})$. Anal. Calcd. for $\mathrm{C}_{236} \mathrm{H}_{198} \mathrm{O}_{43}$ : 
C, 76.16; H, 5.36. Found: C, 76.30; H, 5.23. HRMS (ES+): $m / z$ calculated: 3719.3307 ; found: $3744.3462(\mathrm{M}+\mathrm{Na})^{+}$.

\section{$\alpha, \alpha-D-T r e h a l o s e ~ o c t a k i s(2,3,4-t r i h y d r o x y b e n z o a t e)(31)$}

Following the general deprotection procedure the benzyl protected derivative $30(100 \mathrm{mg}$, $0.026 \mathrm{mmol}$ ) gave $40 \mathrm{mg}$ of a yellow oil that was purified by trituration with dichloromethane to give $21.5 \mathrm{mg}$ (54\% yield) of 31 as a green solid. $\mathrm{Mp} 241-243{ }^{\circ} \mathrm{C}$. $[\alpha]^{20}{ }_{\mathrm{D}}+1.62\left(\mathrm{c} 0.86, \mathrm{CH}_{3} \mathrm{OH}\right)$; ${ }^{1} \mathrm{H}-\mathrm{NMR}\left[\mathrm{CD}_{3} \mathrm{OD}, 400 \mathrm{MHz}\right] \delta 4.18-4.31$ (m, 6H, H-6, H-6', H-5, H-5'), 5.51 (dd, $J=3.6 \mathrm{~Hz}, J$ $\left.=10.1 \mathrm{~Hz}, 2 \mathrm{H}, \mathrm{H}-2, \mathrm{H}-2^{\prime}\right), 5.67$ (t, $J=9.7 \mathrm{~Hz}, 2 \mathrm{H}, \mathrm{H}-4, \mathrm{H}-4$ '), 5.89 (d, $J=3.7 \mathrm{~Hz}, 2 \mathrm{H}, \mathrm{H}-1, \mathrm{H}-$ 1'), 6.20 (t, $J=9.9 \mathrm{~Hz}, 2 \mathrm{H}, \mathrm{H}-3, \mathrm{H}-3$ '), 6.32 (d, $J=9.0 \mathrm{~Hz}, 2 \mathrm{H}, \mathrm{H}-\mathrm{Ar}), 6.38$ (d, $J=9.0 \mathrm{~Hz}, 2 \mathrm{H}$, H-Ar), 6.44 (d, $J=9.0 \mathrm{~Hz}, 2 \mathrm{H}, \mathrm{H}-\mathrm{Ar}), 6.47$ (d, $J=9.0 \mathrm{~Hz}, 2 \mathrm{H}, \mathrm{H}-\mathrm{Ar}), 6.97$ (d, $J=9.0 \mathrm{~Hz}, 2 \mathrm{H}$, H-Ar), 7.18 (d, $J=9.0 \mathrm{~Hz}, 2 \mathrm{H}, \mathrm{H}-\mathrm{Ar}), 7.27$ (d, $J=9.0 \mathrm{~Hz}, 2 \mathrm{H}, \mathrm{H}-\mathrm{Ar}), 7.48$ (d, $J=9.0 \mathrm{~Hz}, 2 \mathrm{H}$, H-Ar). ${ }^{13} \mathrm{C}-\mathrm{NMR}\left[\mathrm{CD}_{3} \mathrm{OD}, 100 \mathrm{MHz}\right] \delta 63.58\left(2 \mathrm{CH}_{2}\right), 70.14(2 \mathrm{CH}), 70.47(2 \mathrm{CH}), 71.89(2 \mathrm{CH})$, $72.66(2 \mathrm{CH}), 93.31(2 \mathrm{CH}), 105.08(\mathrm{C}), 105.13(\mathrm{C}), 105.45(\mathrm{C}), 106.00(\mathrm{C}), 109.30(\mathrm{CH}), 109.37$ $(\mathrm{CH}), 109.96(\mathrm{CH}), 110.07(\mathrm{CH}), 123.04(\mathrm{CH}), 123.15(\mathrm{CH}), 123.24(\mathrm{CH}), 123.62(\mathrm{CH}), 133.98$ (C), 134.09 (C), 134.41 (C), 152.71 (C), 152.85 (C), 153.00 (C), 153.44 (C), 153.89 (C), 154.07 (C), $154.36(\mathrm{C}), 170.46(\mathrm{C}=\mathrm{O}), 170.75(\mathrm{C}=\mathrm{O}), 171.04(\mathrm{C}=\mathrm{O}), 171.27(\mathrm{C}=\mathrm{O}) . \mathrm{MS}(\mathrm{ES}+): \mathrm{m} / \mathrm{z}$ 1559.2 $(\mathrm{M}+\mathrm{H})^{+}, 771.2$ (break for the anomeric C) ${ }^{+}$. HRMS (ES+): $m / z$ calculated: 1558.2039; found:1559.2057 $(\mathrm{M}+\mathrm{H})^{+}$.

\section{Biological Assays}

\section{CMG2-PA FRET Assay}

\section{Assay Protocol}


The CMG2-PA FRET assay was performed as described in Rogers et al. ${ }^{12}$ Specifically, compound was dissolved in DMSO at $10 \mathrm{mM}$ and this stock solution was stored frozen at $-20^{\circ} \mathrm{C}$. On the day of the assay, the stock solution was thawed and diluted 25:1 in CaHBST (20 mM 4-2hydroxyethyl)-1-piperazineethanesulfonic acid (HEPES) pH 7.4, $150 \mathrm{mM} \mathrm{NaCl}, 0.1 \mathrm{mM} \mathrm{CaCl}$, $0.1 \%$ Tween-20). Duplicate 1:1 serial dilutions in $10 \mu 1$ were made using a Precision 2000 robot in Corning 3573 black, polystyrene, 384-well plates, columns 3-23. Column 1 contains CaHBST, column 2 contains CaHBST+EDTA $(20 \mathrm{mM})$. Columns $23 \& 24$ contain the same solution. To this plate, which now contains $10 \mu /$ well, was added $20 \mu 11.5$ nM CMG2-AF546 using a Wellmate plate filler. The Wellmate was then used to add $10 \mu 1$ 32nM PA-AF488 and the resulting solution was incubated for 4 hours. An Envision plate reader was used to measure fluorescence. Excitation was with a 485/14 nm filter. Emission was with 535/25 nm and 595/60 nm filters.

\section{Data Analysis}

Data was filtered to remove optical artifacts by disregarding data points in which both Em595 and Em535 decreased below that of column 1 (interaction) control points. Then a FRET ratio (Em595/Em535) was calculated for each well. For each well, column 1 (interaction), and column 2 (EDTA, no interaction) controls were used to calculate \% inhibition, with mean $595 / 535$ used for $100 \%$ and $0 \%$ interaction, respectively. As is true for PGG (1), for several compounds, we observed a loss of inhibition at high concentrations, ${ }^{13}$ thus data were filtered to remove points after the minimum was achieved for a given dilution series. $\mathrm{IC}_{50}$ and $95 \%$ confidence interval was calculated for each compound exhibiting substantial inhibition using 
GraphPad Prism version 5.01, fitting top, bottom, and $\mathrm{IC}_{50}$ and constraining the Hill coefficient to 1 . Compounds with no apparent activity are reported with $\mathrm{IC}_{50}>10 \mu \mathrm{M}$.

\section{Bio-layer interferometry interaction analysis}

\section{Expression and Purification of CMG2-GST}

CMG2-GST was expressed and purified as described previously. ${ }^{26}$ Briefly, CMG2 40-217 (with R40C and C175A mutations) was expressed as a GST-fusion in pGEX 4T-1 (Amersham Biosciences) in T7 Express E. coli (New England Biolabs). After bioreactor expression, cells were harvested and lysed by 5 passes through a French press. The cleared lysate was loaded onto agarose-glutathione beads (Pierce) and purified according to manufacturer instructions, including washing with Tris buffer and elution with Tris buffer containing $10 \mathrm{mM}$ glutathione. Purity was determined as $>85 \%$ by SDS-PAGE and colloidal Coomassie staining. ${ }^{27}$ Glutathione was removed and the purified CMG2-GST was exchanged into 50mM HEPES, $150 \mathrm{mM} \mathrm{NaCl}, 0.05 \%$ Tween-20, $\mathrm{pH} 7.2,0.02 \% \mathrm{NaN}_{3}$, with 50\% glycerol using a Sephadex G50 column (Amersham Biosciences) in line with an Äkta Start protein purification system. Purified protein was stored at $-80{ }^{\circ} \mathrm{C}$. PA was used as a positive control and was purified as described previously. ${ }^{26}$

\section{Assay Protocol}

All analyses were performed using an Octet Red96 bio-layer interferometer. Results were collected using Octet 8.1 Data Acquisition software, and afterwards analyzed by global fitting of the data in Octet Data Analysis 8.1 software. Plate shake speed for all assays was $1000 \mathrm{rpm}$.

First, aminopropylsilane (APS) biosensors (Pall FortéBio) were hydrated with HEPESbuffered saline (HBS, $50 \mathrm{mM}$ HEPES, $150 \mathrm{mM} \mathrm{NaCl}, 1 \mathrm{mM} \mathrm{MgCl} 2,1 \mathrm{mM} \mathrm{CaCl}$, and $0.02 \%$ 
$\mathrm{NaN}_{3}$ ) for at least 10 minutes prior to use. Then, PGG and analogs were diluted in the same HBS as above, and these dilutions were used to adsorb PGG and analogs onto the hydrated APS biosensors. Immobilization density was optimized and chosen as the minimum density required to achieve the desired association signal, following manufacturer recommendations. It was determined that variable loading densities did not affect the observed $\mathrm{K}_{\mathrm{d}}$. Concentration required to reach optimal loading density $(0.3-0.7 \mathrm{~nm})$ varied by molecule of interest. All loading concentrations fell within the range of $0.4-4 \mu \mathrm{M}$, and loading times were $300-400$ seconds. This immobilization was likely mediated through a combination of electrostatic and hydrophobic interactions, and it was not surprising that propensity to load onto the APS sensor varied by molecule.

The loading was followed by a 600 -second equilibration/baseline step, performed in the assay buffer (HBS as above, with $0.1 \%$ Tween-20 and a vehicle control dilution series to mimic the addition of sample buffer in the sample wells). After the baseline step, the association of CMG2GST to PGG/analog-loaded sensors was probed using a dilution series consisting of 15,5 , and $1.7 \mathrm{nM}$ CMG2. The association proceeded for 180 - 300 seconds. After association, the sensors were moved back into the baseline/dissociation wells for 400 - 900 seconds to observe dissociation. To accurately fit the data, at least $5 \%$ dissociation had to be observed. Data was collected for PGG and each analog in $3-5$ replicate trials.

\section{CellASIC microfluidic chemotactic migration}

EA.hy926 cells were maintained in 10\% FBS in DMEM according to the American Type Culture Collection (ATCC) instructions. Cells (30,000 in $10 \mu \mathrm{L}$ medium) were seeded into the migration channel of CellASIC ONIX microfluidic gradient plates (Millipore, Hayward, CA) at 
0.4 psi for 25 seconds; then $10 \%$ FBS medium was flowed from the side channels at 0.4 psi overnight. On the next day, fluid flow on the side channels was changed to 10\% FBS DMEM on one side and serum free DMEM on the other. Cell migration was monitored with time-lapse microscopy at $10 \mathrm{X}$ magnification and $2 \times 2$ binning. Images were acquired every 10 minutes for 12 hours, then imported into Image $\mathrm{J}$ and analyzed with the manual tracking plugin. Forty (40) cells were tracked in each replicate. Cell track data was then imported into Chemotaxis and Migration Tools (ibidi.com), to obtain y-displacement data.

\title{
Measurement of angiogenesis in vivo
}

The corneal micropocket angiogenesis assay was performed as previously described ${ }^{28}$ in compliance with a protocol approved by the Boston Children's Hospital Institutional Animal Care and Use Committee. In summary, slow release pellets containing $80 \mathrm{ng}$ of bFGF were implanted in the cornea of $\mathrm{C} 57 \mathrm{BL} / 6 \mathrm{~J}$ mice $\sim 1.0 \mathrm{~mm}$ from the temporal limbus using a modified von Graefe knife. The area of vascular response was assessed on the sixth postoperative day using a slit lamp. Vessel area was calculated using vessel length from the limbus and clock hours around the cornea. For compound treatments, PGM and analogs were dissolved in a mixture of 12.5\% DMSO, 37.5\% N-Methyl-2-pyrrolidone, 25\% Tween 80 and 25\% Cremophor EL. This solution was then diluted 5:1 in saline and injected at a final dose of $10 \mathrm{mg} / \mathrm{kg}$ intraperitoneally. Control animals received vehicle (DMSO/NMP/Tween/Cremophor, diluted in saline).

\section{Associated Content}

\author{
Supporting Information
}


Details regarding the structural assignments, dose-response curves determined by the FRET interaction assay and ${ }^{1} \mathrm{H}$ and ${ }^{13} \mathrm{C}$ NMR spectra of the most representative compounds are included. Molecular Formula Strings of the novel synthesized compounds are also available.

\section{Corresponding author Information}

A. San-Félix: Phone: + 3491 2587617, E-mail: anarosa@iqm.csic.es

M. Rogers: Phone: +1-617-919-2252, E-mail: michael.rogers@tch.harvard.edu

\section{ORCID}

A. San-Félix: 0000-0003-4271-7598

E. G-Doyagüez: 0000-0002-3802-1726

M. Rogers: 0000-0002-5250-8434

\section{Current author addresses}

$¥$ P. Carrero. Current address: Laboratorios Liconsa, S.A., 10200 Azuqueca de Henares Guadalajara, Spain

${ }^{\gamma}$ A. Madrona. Current address: Novartis Farmacéutica S.A., $\underline{08013}$ Barcelona, Spain

${ }^{\pi}$ B. Martínez-Gualda. Current address: Rega Institute for Medical Research, Laboratory of Medicinal Chemistry, 3000 Leuven, Belgium

${ }^{\varphi}$ J.G.Finnell. Current address: Center for Alzheimer's and Neurodegenerative Diseases, University of Texas Southwestern Medical Center, Dallas, TX $\underline{75390}$, USA $\underline{75390}$

${ }^{\lambda}$ P. Rodríguez-Salamanca. Current address: Instituto de Investigaciones Químicas, 41092 Sevilla, Spain 
Author contributions

${ }^{\#}$ E. G.-Doyagüez. and P. Carrero contributed equally to this work

\section{Acknowledgments}

This work was supported by the Spanish MINECO [Project SAF2015-64629-C2-1-R (MINECO/FEDER)], the Spanish Agencia Estatal Consejo Superior de Investigaciones Científicas (CSIC, Project CSIC201680E079) and NIH R01 EY018829. The Spanish MINECO is also acknowledged for a grant to Belén M.-G

Abbreviations used

Capillary Morphogenesis Gene 2 (CMG2); Förster resonant energy transfer (FRET); Protective Antigen (PA); 1,2,3,4,6-penta- $O$-galloyl- $\beta$-D-glucopyranose (PGG); 1,2,3,4,6-penta- $O$-galloyl- $\beta$ D-mannopyranose (PGM); Human Umbilical Vein Endothelial Cells (HUVEC); biolayer interferometry (BLI); basic fibroblast growth factor (bFGF); CaHBST (20 mM HEPES pH 7.4, $150 \mathrm{mM} \mathrm{NaCl}, 0.1 \mathrm{mM} \mathrm{CaCl}_{2}, 0.1 \%$ Tween-20); 4-(2-hydroxyethyl)-1-piperazineethanesulfonic acid (HEPES); HEPES buffered saline (HBS); aminopropylsilane (APS); Dulbecco's Modified Eagle's Medium (DMEM); American Type Culture Collection (ATCC)

\section{References}

1. Senger D.R.; Davis G.E. Angiogenesis. Cold Spring Harb. Perspect. Biol. 2011, 3, a005090. 
2. Folkman J. Tumor angiogenesis: A possible control point in tumor growth. Ann. Intern. Med. 1975, 82, 96-100.

3. Folkman J.; Watson K.; Ingber D.; Hanahan D. Induction of angiogenesis during the transition from hyperplasia to neoplasia. Nature 1989, 339, 58-61.

4. D'Amato R.J.; Adamis AP. Angiogenesis inhibition in age-related macular degeneration. Ophthalmology 1995, 102, 1261-1262.

5. Adamis A.P.; Aiello L.P.; D’Amato R.J. Angiogenesis and ophthalmic disease. Con formato: Inglés (Estados Unidos) Angiogenesis 1999, 3, 9-14.

6. Folkman J. Angiogenesis: An organizing principle for drug discovery?, Nat. Rev. Drug Discov. 2007, 6, 273-286.

7. Carmeliet P.; Jain R.K. Principles and mechanisms of vessel normalization for cancer and other angiogenic diseases. Nat. Rev. Drug Discov. 2011, 10, 417-427.

8. Heath V.L.; Bicknell R. Anticancer strategies involving the vasculature. Nat. Rev. Clin. Oncol. 2009, 6, 395-404.

9. Rogers M.S.; Christensen K.A.; Birsner A.E.; Short S.M.; Wigelsworth D.J.; Collier R.J.; D'Amato R.J. Mutant anthrax toxin B moiety (protective antigen) inhibits angiogenesis and tumor growth. Cancer Res. 2007, 67, 9980-9985.

10. Cryan L.M.; Rogers M.S. Targeting the anthrax receptors, TEM-8 and CMG-2, for antiangiogenic therapy. Front. Biosci. 2011, 16, 1574-1588. 
11. Bradley K.A.; Mogridge J.; Mourez M.; Collier R.J.; Young J.A. Identification of the cellular receptor for anthrax toxin. Nature 2001, 414, 225-229.

12. Rogers M.S.; Cryan L.M., Habeshian K.A., Bazinet L., Caldwell T.P., Ackroyd P.C., Christensen K.A. A FRET-based high throughput screening assay to identify inhibitors of anthrax protective antigen binding to capillary morphogenesis gene 2 protein. PLOS One 2012, 7, e39911.

13. Cryan L.M.; Bazinet L.; Habeshian K.A.; Cao S.; Clardy J.; Christensen K.A.; Rogers M.S. 1,2,3,4,6-Penta- $O$-galloyl- $\beta$-D-glucopyranose inhibits angiogenesis via inhibition of capillary morphogenesis gene 2. J. Med. Chem. 2013, 56, 1940-1945.

14. Neises B.; Steglich W. 4-Dialkylaminopyridines as acylation catalysts .5. Simple method for esterification of carboxylic-acids. Angew. Chem-Int. Ed. 1978, 17, 522-524.

15. Ren Y.L.; Himmeldirk K.; Chen X.Z. Synthesis and structure-activity relationship study of antidiabetic penta-O-galloyl-D-glucopyranose and its analogs. J. Med. Chem. 2006, 49, 28292837.

16 Khanbabaee K.; Lötzerich K. Efficient Total Synthesis of the Natural Products 2,3,4,6Tetra- $O$-galloyl-D-gluco-pyranose, $\quad 1,2,3,4,6$-Penta- $O$-galloyl- $\beta$-D-glucopyranose and the Unnatural 1,2,3,4,6-Penta-O-galloyl- $\alpha$-D-glucopyranose. Tetrahedron 1997, 53, 10725-10732.

17. He Q.; Shi B.; Yao K.; Luo Y.; Ma Z.H. Synthesis of gallotannins. Carbohydr. Res. 2001, 335, 245-250.

18. Morris S.G.; Riemenschneider R.W. The higher fatty alcohol esters of gallic acid. J. Am. Chem. Soc. 1946, 68, 500-501. 
19. Schmidt O.T.; Schach A. Synthese der 3-Galloyl-glucose, 6-Galloyl-glucose und 3,6Digalloyl-glucose. 8. Mitteilung uber naturliche Gerbstoffe. Annalen Der Chemie-Justus Liebig Ann. Chem. 1951, 571, 29-41.

20. Belin F.; Barthelemy P.; Ruiz K.; Lacombe J.M.; Pucci B. Synthetic gallic acid derivatives as models for a comprehensive study of antioxidant activity. Helv. Chim. Acta 2003, $86,247-265$.

21. Takashi N.; Kumiko K.; Akiko A.; Kenji M.; Koichiro T. Prophylactic and Therapeutic Agent for Bone Diseases containing Hydroxybenzoic Acid Amide Derivative as Active Agent, Japan Patent JP 08-143525 (A), Date of publication of application: June 04,1996.

22. Duus J.O.; Gotfredsen C.H.; Bock K. Carbohydrate structural determination by NMR spectroscopy: Modern methods and limitations. Chem. Rev. 2000, 100, 4589-4614.

23. Bubb W.A. NMR spectroscopy in the study of carbohydrates: Characterizing the structural complexity. Concepts Magn. Reson. Part A 2003, 19A (1): 1-19.

24. Hurd R.E; John B.K. Gradient-enhanced proton-detected heteronuclear multiple-quantum coherence spectroscopy. J. Magn. Reson. 1991, 91, 648-653.

25. Kay L.E.; Keifer P.; Saarinen T. Pure absorption gradient enhanced heteronuclear single quantum correlation spectroscopy with improved sensitivity. J. Am. Chem. Soc. 1992, 114, 10663-10665.

26. Wigelsworth D.J.; Krantz B.A.; Christensen K.A.; Lacy D.B.; Juris S.J.; Collier R.J. Binding stoichiometry and kinetics of the interaction of a human anthrax toxin receptor, CMG2, with protective antigen. J. Biol. Chem. 2004, 279, 23349-23356. 
27. Dyballa N.; Metzger S. Fast and Sensitive Colloidal Coomassie G-250 Staining for Proteins in Polyacrylamide Gels. J. Vis. Exp. 2009, 1431. doi: 10.3791/1431.

28. Rogers M.S.; Birsner A.E.; D'Amato R.J. The mouse cornea micropocket angiogenesis assay. Nat. Protoc. 2007, 2, 2545-2550.

\section{Table of Contents graphics}

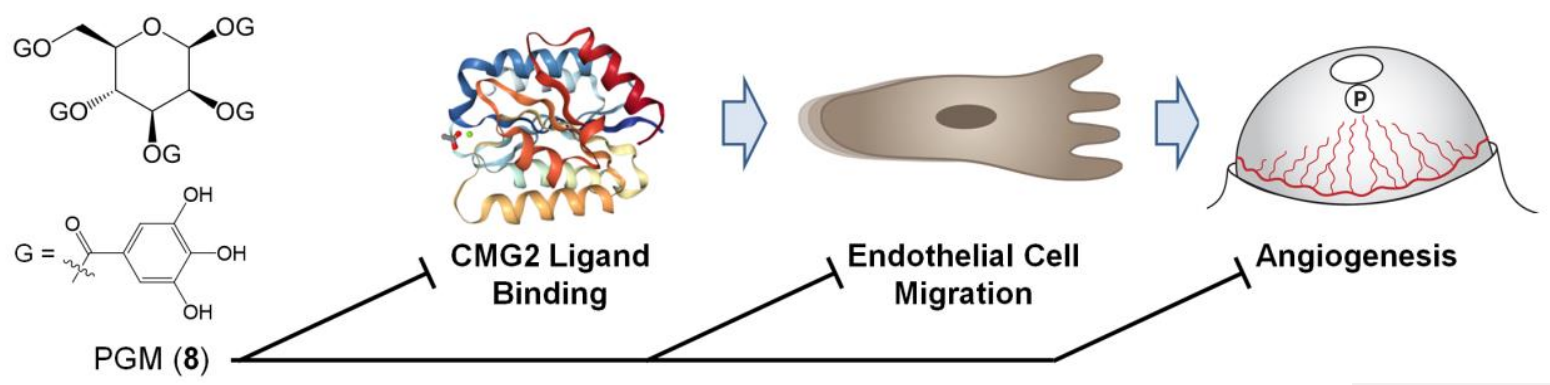

